The Sources and Consequences of Embeddedness for the Economic Performance of Organizations: The Network Effect*

Brian Uzzi*

Northwestern University

Running Head: Embeddedness and the Economic Performance of Organizations

American Sociological Review, Ms. \#94-289

Total word count: 13,258

27 March, 2000

*Direct correspondence to Brian Uzzi, Department of Organization Behavior, J. L. Kellogg Graduate School of Management, Northwestern University, Evanston, IL 60208-2011 (uzzi@nwu.edu). I thank Gerald Davis, Roberto Fernandez, Mark Granovetter, Ranjay Gulati, Marika Lindholm, Chick Perrow, Frank Romo, Michael Schwartz, Marc Ventresca, Ed Zajac, and the ASR Editors and anonymous reviewers for their comments on this paper. Grants from the National Science Foundation (SES-9200960 and SES-9348848), Sigma Xi Scientific 
Research Society, and Institute for Social Analysis at the State University of New York at Stony Brook supported this research. Portions of this paper extend unpublished research which has received the 1991 American Sociological Association's James D. Thompson Award, the 1993 Society for the Advancement of Socio-Economics Best Paper Prize, and 1994 Academy of Management's Louis Pondy Dissertation Award. 


\section{The Sources and Consequences of Embeddedness for the Economic Performance of Organizations: \\ The Network Effect}

\section{ABSTRACT}

In this paper, I attempt to advance the concept of embeddedness beyond the level of a programmatic statement by developing a formulation that specifies how embeddedness and network structure affect economic action. On the basis of existing theory and original ethnographies of 23 apparel firms, I develop a systematic scheme that more fully demarcates the unique features, functions, and sources of embeddedness. From this scheme, I derive a set of refutable implications and test their plausibility, using another data set on the network ties of all better dress apparel firms in the New York apparel economy. Results reveal that embeddedness is an exchange system with unique opportunities relative to markets and that firms organized in networks have higher survival chances than do firms which maintain arm's-length market relationships. The positive effect of embeddedness reaches a threshold, however, after which point the positive effect reverses itself. 
There is a growing need to understand how social structure assists or impedes economic performance. In particular, the success of organization networks has spawned new conjectures about the competitive advantage of social forms of organization relative to market-based exchange systems (Powell 1990; Inzerilli 1991; Perrow 1992). Central to these conjectures is the "embeddedness" argument, which offers a potential link between sociological and economic accounts of business behavior. Embeddedness refers to the process by which social relations shape economic action in ways that some mainstream economic schemes overlook or misspecify when they assume that social ties affect economic behavior only minimally or, in some stringent accounts, reduce the efficiency of the price system (Granovetter 1985; Crosby and Stephens 1987). Although the concept of embeddedness is useful for understanding the sociological failings of standard neoclassical schemes, it does not explain concretely how social ties affect economic outcomes. The core statement--that economic action is embedded in social relations which sometimes facilitate and at other times derail exchange--is conceptually vague. It forestalls a clear comparison between the refutable propositions of current theories and the broad statements describing how embeddedness shapes personal motives and collective order (Williamson 1994).

My aim is to advance the concept of embeddedness beyond the level of a programmatic statement by formulating a scheme that specifies how embeddedness and network structure affect economic behavior. First, I develop a scheme based on existing theory and original ethnographic analysis that describes the features, functions, and sources of embeddedness. Second, from this scheme I derive refutable implications and statistically test their plausibility using another data set on network ties among "better dress" firms in the New York apparel economy. The goal is not to establish a positivist proof of the 
framework; rather I aim to demonstrate its plausibility and how it helps us to understand the effect of social structure on economic life.

I argue that organizational networks operate in an embedded logic of exchange which promotes economic performance through interfirm resource pooling, cooperation, and coordinated adaptation, but which also can derail performance by sealing off firms in the network from new information or opportunities that exist outside the network. An organization's network position, network structure, and distribution of embedded exchange relationships shape performance such that performance reaches a threshold as embeddedness in a network increases. After that point, the positive effect of embeddedness reverses itself.

I focus the analysis in two ways. First, I concentrate on the concept of structural embeddedness that concerns the material quality and structure of ties among actors. ${ }^{1}$ Second, I examine organization performance by comparing firms that operate in organization networks with those that operate in arm'slength markets. This comparison is aptly applied to New York's apparel industry: Because of the low barriers to entry, the low start-up costs, the low search costs, and the many substitutable shops, this industry approximates the ideal conditions under which atomistic market exchange relationships should be most successful relative to alternate forms of organization (Roberts 1989; Wilson 1989; $\mathrm{M}^{\mathrm{C}}$ Lean and Padgett forthcoming).

\footnotetext{
1 Zukin and DiMaggio (1990) classify embeddedness into four forms: (1) structural as described above; (2) cognitive--structured mental processes that direct economic logic; (3) cultural--shared beliefs and values that shape economic aims; and (4) political--institutional limits on economic power and incentives. In this typology, the last three denote embeddedness as a social context, whereas structural embeddedness focuses on the relational quality of interactor exchanges and the architecture of network ties.
} 
The data also deserve special mention. While embeddedness research has been criticized for using data on immigrant enclaves, which favor the embeddedness thesis (Portes and Sensenbrenner 1993), this research uses data on the modern apparel industry which is multicultural and populated by a diverse group of degree-holding management and marketing professionals (Waldinger 1986). In this industry, interfirm transactions also tend to be conducted between different groups: Manufacturers tend to be Italian or Jewish, and contractors, Chinese; low barriers to entry and the great number of substitutable shops further minimize enclaving (Portes and Sensenbrenner 1993). Another advantage of these data is that the departmental biases that can distort interviewee's views in complex firms were partly controlled because the CEOs and management personnel whom I interviewed were involved in all key aspects of the business. Finally, the analysis combines the strengths of ethnography and the statistical analysis of large sample network data to examine the effects of tie content and structure on economic performance.

\section{THEORY: TOWARD A STRUCTURAL EMBEDDEDNESS APPROACH}

In the structural embeddedness approach advanced here, I combine organization theory with social network theory (Romo and Schwartz 1995) and argue that the structure and quality of social ties among firms shape economic action by creating unique opportunities and access to those opportunities. The type of network in which an organization is embedded defines the opportunities potentially available; its position in that structure and the types of interfirm ties it maintains define its access to those opportunities. At one extreme, interfirm networks may be composed of loose collections of firms. These structures resemble prototypical markets and tend to be impersonal, diffuse, and shifting in membership (Baker 1990). At the other extreme, networks are composed of finite, close-knit groups of firms. These 
structures represent the typical notion of an organization network as a set of firms that maintain ongoing and exclusive relationships with one another. When firms keep arm's-length ties with one another, the pattern of exchanges produces a market-like structure; when they maintain embedded ties, the pattern of exchange produces a network (Powell 1990).

A key feature of my approach is the idea that organization networks operate on a logic of exchange which differs from the logic of markets. I refer to this exchange logic as "embeddedness" because ongoing social ties shape actors' expectations and opportunities in ways that differ from the economic logic of market behavior. "Embeddedness refers to the fact that exchanges within a group...have an ongoing social structure [which]...by constraining the set of actions available to the individual actors and by changing the dispositions of those actors toward the actions they may take" (Marsden 1981:1210) affects economic performance in ways that some orthodox and neoinstitutional economic schemes do not address. The key implication is that the level of embeddedness in an exchange system produces opportunities and constraints which are particular to network forms of organizations and which result in outcomes not predicted by standard economic explanations.

The Problem of Embeddedness in Markets and Networks

Research in economics, sociology, and history assumes that the exchange system against which other organizing forms are measured is the idealized atomistic market, which links actors through arm's-length ties (Hirschman 1970; Roberts 1989; Wilson 1989; Williamson 1994). The features of arm's-length exchange are well established (North 1990) and although understood to be ideal, they are taken in practice as truisms: "Economists have...tended to regard the idealized model as giving a basically correct view... This traditional faith in the efficacy of markets partly reflected a judgment about reality; equally it 
reflected a lack of any ability to describe precisely what difference deviation from perfect markets make[s]" (Krugman 1991:78). According to market theory, selfish, profit-seeking behavior motivates action in arm'slength relationships. The transaction itself is limited to the exchange of data on price and quality because it contains all the information needed to make efficient decisions--especially in competitive industries such as apparel, where the unconcentrated market structure and the many substitutable firms should make social attachments immaterial. "But whether markets are characterized by perfect competition or bilateral monopoly, the necessary and sufficient condition for the existence of a market is the impersonal relation between buyer and seller" (Lazonick 1991:60). Impersonal relations and loose structural coupling are thought to optimize efficiency by facilitating access to market information and by averting asset-specific/small-numbers bargaining situations that impede unilateral action and add needless coordination costs to interfirm exchanges.

Revisions to neoclassical theory have made sophisticated additions to these first principles, particularly in regard to how bounded rationality, imperfect information, and small-numbers bargaining situations can cause the definitive efficiency of markets to be supplanted by hierarchies or hybrid organization forms. In these frameworks, however, the view that social relations are essentially peripheral to economic performance remains the same as in the neoclassical model. The focus continues to be on self-interested, profit-maximizing motives, external incentives, hostage taking, enforceable contracts, and impersonal relationships (North 1990; Lazonick 1991). For example, transaction cost economists argue that concepts such as trust and reciprocity only muddy the clear waters of economic analysis--discounting key sociological variables (Williamson 1994). Moreover, as Williamson notes (1994:85), "transaction cost economics is preoccupied with dyadic relations, 
so that network relations are given short shrift." Agency theorists also find it difficult to explain organizational networks because the roles of principal and agent are non-distinct and because of an absence of the type of governance mechanisms that form the basis for agency theory predictions (Larson 1992 ). Thus, neo-economic arguments offer alternatives to neoclassical principles under special conditions; nonetheless, they view social structure as having only a marginal effect on performance relative to the impersonal, external incentive-based logic of market transacting.

In contrast, network theory argues that embeddedness shifts actors' motivations away from the narrow pursuit of immediate economic gains to the enriching of relationships through trust and reciprocity (Powell 1990; Smitka 1991). Trust helps reduce transactional uncertainty and creates opportunities for the exchange of goods and services that are difficult to price or enforce contractually. Other research has shown that identity matters in embedded relationships because it assigns value to the transaction and enriches the social capital of exchange partners in the network (Portes and Sensenbrenner 1993). Larson (1992) and Helper (1990) reported that "thicker information" on strategy, production know-how, and profit margins is transferred through embedded ties, thus promoting learning and integrated production in ways that the exchange of only price data cannot. Romo and Schwartz's (1995) research on organizational migration suggests that firms embedded in interfirm networks use integrating mechanisms to solve problems of coordination and adaptation. The main implication of these findings is that interfirm networks facilitate the creation of important economic outcomes. Nonetheless, the mechanisms that produce these benefits are vaguely specified and empirically still incipient (Powell 1990). 
To explore the implications of the structural embeddedness argument, I first conducted an ethnographic study consisting of interviews with the CEOs and select staff members off 23 New York-based apparel firms with annual sales between $\$ 500,000$ and $\$ 1$ billion, for a total of 117 hours of interviews with 43 persons. I selected firms on the basis of a stratified random sampling procedure; the interfirm relationship was the unit of analysis. Ethnography is advantageous for studying embeddedness because it enables the researcher to understand the causes, consequences, and mechanisms by which social structure affects economic outcomes, and provides a rich source of data for generating specific, testable hypotheses. As explained in detail in the Appendix, the ethnographic analysis consisted of systematically traveling back and forth between the field data and the above-mentioned framework such that some elements of the framework were refined, while others were modified or dropped in accordance with the fieldwork.

Findings: The Features and Functions of Embedded Ties Interviewees believed that the content and structure of ties among firms directly affected social and economic behavior, that an actor's level of embeddedness varied from low to high depending on the type of interfirm ties he or she maintained, and that the different accounts of exchange relationships could be defined accurately by two elementary forms of exchange, which interviewees referred to as "market" or "arm's-length" relationships and "special" or "close" relationships. In keeping with neoclassical theory, arm's-length relationships conformed closely to the idealized concept and typically were described in the sharp, impersonal terms that reflected the nature of the transaction: "They" re the one-shot deals;" "a deal in which costs are everything;" "You discuss only money;" "It's the opposite (of a 
close relationship); "one hand doesn't wash the other;" "They' re relationships that are like far away. They don't consider the feeling for the human being." In contrast, interviewees reflected the concept of embeddedness in what they called "special" or "close" relationships, as in these typical responses: "It is hard to see for an outsider that you become friends with these people-business friends. You trust them and their work. You have an interest in what they're doing outside of business. They know that they're like part of the company. They're part of the family." More important, I found that embedded ties perform unique functions and have three features: trust, finegrained information transfer, and joint problem-solving arrangements. These features are mutually reinforcing and are counterparts to the features of arm's-length ties (see also Uzzi 1996). In the next section I describe these patterns in detail and discuss the mechanisms by which embedded ties facilitate economic exchange. I then test statistically the main propositions that follow from the fieldwork.

Trust. The field research revealed that trust acted as the governance mechanism of embedded relationships. It facilitated the exchange of resources and information that are crucial for high performance but are difficult to value and transfer via market ties. One manufacturer said, "Trust is the distinguishing characteristic of a personal relationship." Another typical response was "Trust means he's not going to find a way to take advantage of me. You are not selfish for your own self. The company and partnership (between firms) comes first.

I found that trust is a unique governance mechanism in that it promotes voluntary, non-obligating exchanges of assets and services between actors. These exchanges might entail special treatment on a rush job or giving business to an exchange partner to help him or her fill capacity. Consequently, a significant outcome of trust is that it facilitates the 
extension of benefits to transacting partners and invites the receiving partner to reciprocate when a new situation arises. The particular quality of these transactions is that they are not easily priced at a "cash value" or bound by contracts; no exact repayment or penalty is devised a priori. This situation creates an open architecture of exchange which promotes the exchange of services that are critical for survival but are difficult to price or specify contractually beforehand. For example, a manufacturer said, "With people you trust, you know that if they have a problem with a fabric they're just not going to say 'I won't pay' or 'Take it back'. If they did, then we would have to pay for the loss. This way maybe the manufacturer will say 'Hey, OK, so I'll make a dress out of it. Or I can cut it and make a short jacket instead of a long jacket.'" Thus, unlike the impersonal and calculative orientation of arm's-length exchange (Williamson 1994), trust is personal and disposes one to interpret favorably another's intentions and actions. Trust is important because it increases an organization's access to resources and strengthens its ability to adapt to unforeseen problems in ways that are difficult to achieve through arm's-length ties.

Fine-grained information transfer. Information exchange in embedded ties is more proprietary and more tacit than the information exchanged at arm's-length. It includes strategic, and tacit know-how that boosts a firm's transactional efficacy and responsiveness to the environment. A CEO explained how fine-grained information exchange helps to increase know-how and to reduce problems in ways that are difficult when arm's-length ties are used:

If we have a factory that is used to making our stuff, they know how it's supposed to look. They know a particular style. It is not always easy to make a garment just from the pattern, especially if we rushed the pattern. But a factory that we have a relationship with will see the problem when the garment starts to go together. They will know how to work the fabric to make it look the way we intended. A factory that is new will just go ahead and make it. They won't know any better. 
From a sociological perspective, fine-grained information exchange cannot be explained as a special incident of information asymmetries or asset specificity because the identity of the individuals and the quality of their social tie are as important as the information itself. Social relations make information credible and interpretable, imbuing it with qualities and value beyond what is at hand. In a typical example of the nature of this process, a manufacturer stated that he passes on critical information about next season's hot sellers only to his close ties; thus giving them an advantage in meeting future demands. In this case, the manufacturer's relationship with his embedded ties not only increases the transfer of information, but also makes it interpretable and valuable. The CEO said, "I get on the phone and say to a buyer, 'This group's on fire' [i.e., retail buyers are placing many orders for this design]. But she'll buy it only as long as she believes me. Other people (his competitors) can say it's hot as a pistol, but she knows me. If she wants it, she can come down and get it. The feedback gives her an advantage." Thus the thick information transfer of embedded ties facilitates beneficial types of interfirm coordination and learning in ways that are difficult to emulate in arm's-length exchange.

Joint problem-solving arrangements. I found that embedded ties entail joint problem-solving arrangements that enable actors to coordinate functions and work out problems "on the fly." These arrangements provide more rapid and explicit feedback than do market-based mechanisms such as exit (Hirschman 1970); they enable firms to work through problems and to accelerate learning and problem correction. Much as Helper (1990) and Larson (1992) showed in their studies of interfirm relationships, firms that are linked through embedded ties work through problems and get direct feedback--increasing learning and the discovery of new combinations. As one CEO stated, "When you 
deal with a guy you don't have a long relationship with, it can be a big problem. Things go wrong and there's no telling what will happen. With my guys [referring to embedded ties], if something goes wrong, I know we'll be able to work it out. I know his business and he knows mine." In contrast, I found that in arm's-length ties firms receive no direct feedback when customers use exit strategies; the reasons must be inferred. One typical response was, "They don't want to work with the problem. They just want to say, 'This is how it must be.' Then they switch (to a new firm) again and again." Thus, joint problem-solving arrangements supplant the simple exit/stay response of markets by enabling actors to work through problems on the fly and to innovate; thereby they enrich the network with new solutions and combinations of ideas.

\section{The Formation of Embedded Networks and Behavioral Outcomes}

How do embedded ties develop the characteristics discussed above and combine into networks of organizations? I found that embedded ties develop primarily from third-party referral networks and previous personal relations which (1) set expectations for trust between newly introduced actors and (2) equip the new economic exchange with resources from preexisting embedded ties. With this initial set of expectations and resources, an arm's-length tie tends to be recast into an embedded tie if a trial period of reciprocal exchange results in voluntary contributions of new resources to the relationship and in a concretizing of cooperative expectations. Over time the iterative process progressively becomes independent of the initial economic goals, resulting in an embedded tie. Thus, just as economic transactions are embedded in social relations, new social relationships are partly reverse-embedded in economic transactions: Businesspeople understand that they are in business to profit and that more profit is better than less. The unique quality of these 
exchanges is that economic process follows an embedded rather than an arm'slength logic.

In the firms I studied, third-party referral networks were often cited as sources of embeddedness. Such networks operate by fusion: One actor with an embedded tie to each of two unconnected actors acts as their go-between by using her common link to establish trustworthiness between them. The gobetween performs two functions: he or she (1) transfers expectations of behavior from the existing embedded relationship to the newly matched firms, and (2) "calls on" the reciprocity "owed" him or her by one exchange partner and transfers it to the other. The go-between essentially cedes the expectations and opportunities of an existing embedded social structure to a newly formed structure, thus priming the new relationship for embeddedness. For example, one CEO explained how an embedded tie formed between him and a manufacturer named "Diana." He said that his contact with Diana began when Norman, a close business friend of his and Diana's, asked him "to help Diana out" in a time of need (cut her fabric at a special price and time), even though he had no prior contact with her.

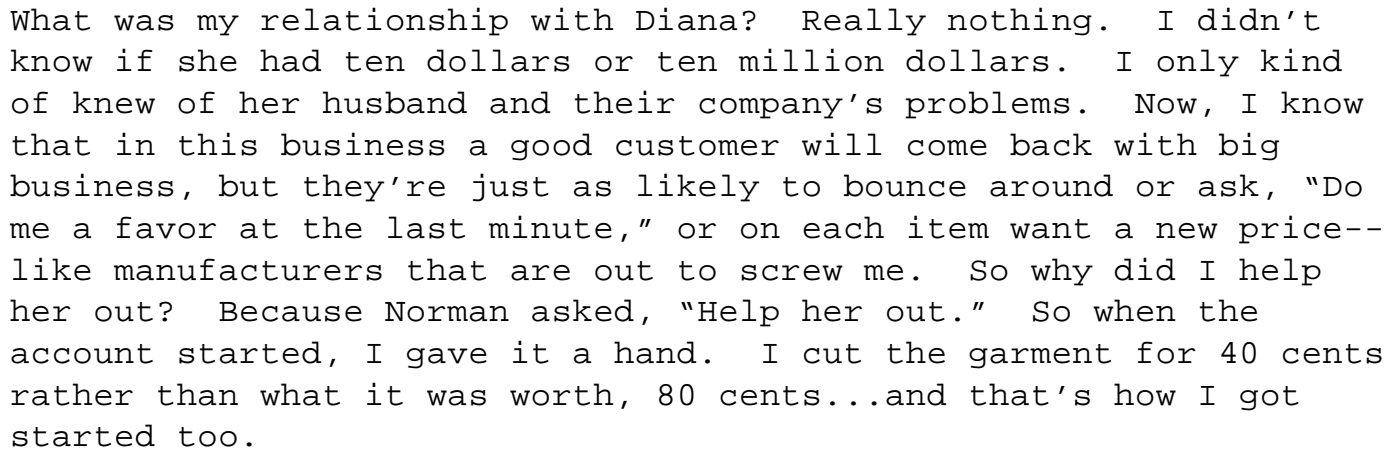


guarantee return business. Diana's production manager explained that the expectations of trust and reciprocity for the new relationship were not discussed but were understood to be extensions of their tie to Norman, the gobetween: "There was no talk of 'one hand washes the other' [she gestured, rolling one hand over the back of the other]. It's understood here." In contrast, she said, arm's-length ties work on a different logic. "They go only by the letter of the contract and don't recognize my extra effort. [for example] I may come down to their factory on Saturday or sunday if there is a problem--I won't even mention it to Diana. I don't mean recognize with money. I mean with working things out to both our satisfaction."

Embedded ties often are established in new interfirm relationships because individuals know one another from other social circles as coworkers, schoolmates, friends, or kin. Like third-party referral networks, previous ties enable resources and open-handed expectations from an existing relationship to be engaged in a new relationship or to elaborate the multiplexity of the relationship. A CEO explained:

We'll set up a boiler or some racks. We'll give them [our contractors] a "gift". [But] we never make gifts to potential startups unless there is a history of personal contact. Never for a stranger. Only for people we have a rapport with. So if Elaine [the manager of a contracting firm to which this CEO sends work] wanted to start her own shop, I would make her a gift. But for some stranger--never. Why should I invest my money on a guy I may never see again?

In this way, both referral networks and previous personal ties facilitate the rise of embedded ties by applying opportunities and expectations from preexisting embedded relations to new relationships and situations.

Finally, the data suggest that embedded ties can originate from anonymous market ties, but that this source of embeddedness is uncommon in 
this industry. For example, a CEO stated, "I will give a firm a chance based on Dun and Bradstreet data. I call the bank and get a financial report on the firm's size. I know this is 'marketing' [the CEO's terms for using market ties], but most contractors don't do marketing [they mainly use firms they know]." Another typical response was "We get resumes from contractors off the street all the time. But I will try a new contractor like that only when we are very busy." This source of embeddedness seemed to be rare because a lack of prior social relations leaves the new tie without initial resources and behavioral expectations that reduce outcome uncertainty. Consequently actors are relatively unlikely to invest, a priori, in cultivating an embedded relationship with unknown actors. As one CEO remarked, "A manufacturer is not going to trust some contractor off the street... And besides, if he gave'em a chance, maybe one in ten would be good. We won't recommend a wrong shop. We know the machinery, what the factory can do." Surprisingly, the use of generalized reputation (i.e., market knowledge of another firm's typical behavior) to match new firms was also less common than expected because reputations were viewed as elusive and contradictory by businesspeople in this industry. Typical responses were "Manufacturers can play hit and run for years before their reputation catches up with them." "I hear 'This one is very picky' or 'This guy is really bad trouble.' But firms I do all the business for, I don't tell a word about the others. I don't want the competition." The weak effect of reputation appeared to result from the high turnover of firms, the size and diversity of the market, and the prevalence of contradictory information, which made reputations difficult to build and signal. This result reinforced the finding that embeddedness was difficult to develop in the absence of a patterned social structure which interpreted mixed signals and transferred beliefs, values, and resources among firms. 
A causal order. The findings suggest that a "primed" relationship develops into ongoing embedded ties in stages that begin with the initial stock of trust appropriated from a preexisting social relation. This stock of trust furnishes a basis for offering and discharging subsequent commitments. If these exchanges are reciprocated, the trust in the relationship becomes concrete. The calculative orientation of arm's-length ties fades and is replaced with a heuristic decision making process that economizes on cognitive resources, speeds up decision making, and inclines actors to interpret favorably the actions and intentions of their network partners in ambiguous situations (see Uzzi 1996 for a fuller treatment of the microbehavioral decision making characteristics of embedded ties). A CEO explained,

You may ship fabric for 500 garments and get only 480 back. So what happened to the other twenty? Twenty may not seem like a lot, but twenty from me and twenty from another manufacturer and so on, and the contractor has a nice little business on the side. of course you can say to the contractor, "What happened to the twenty?" But he can get out of it. [He might say that] Was it the trucker that stole the fabric? He can also say he was shorted in the original shipment from us. So there's no way of know who's to blame for sure. That's why trust is so important.

If trust forms between two actors, a base for fine-grained information transfer is set in place. Such an exchange is unlikely in the absence of trust because information could be used opportunistically (Helper 1990; Larson 1992). Fine-grained information exchange in turn causes firms to reduce their search for alternative information sources or exchange partners, for two reasons. First, the acquisition of information is costly; thus, the more time devoted to information transfer with one party, the less time available for other ties. Second, information that otherwise would be gained through many arm's-length ties is supplied, in a relation of trust, by fewer but more concentrated contacts. Concentrated exchange in turn spawns pressures to form joint problem-solving arrangements that enable firms to maintain the 
continuity of the relationship. These arrangements further intensify the interaction between parties and expose them to dimensions of their relationship which are outside the narrow economic concerns of the exchange but which provide adaptive resources.

In this way, economic exchange becomes embedded in a multiplex relationship composed of economic investments, friendship, and altruistic attachments. The longer the relationship lasts the richer it becomes in debits and credits, creating an opportunity-rich social structure. A CEO epitomized the end product of this relationship-forming process: "If someone needs advertising money, or returns, or a special style for windows, it will be like any relationship. You'll do things for friends. You'll go to the bank on their orders. The idea that 'they buy and we sell' is no good. Friends will be there with you through the bad times and good."

A key behavioral consequence of embeddedness is that it becomes separate from the narrow economic goals which originally constituted the exchange and generates outcomes which are independent of the narrow economic interests of the relationship. I observed this in a diversity of cases. In one incident, a manufacturer who was permanently moving all production to Asia notified those contractors with whom he had an embedded relationship nine months before moving so that they could adapt to the loss of his business. The manufacturer, however, did not inform those contractors with whom he had arm's-length ties. The persistence of the social relationship between the manufacturer and his key contractors is significant because it is at odds with standard economic accounts of the manufacturer's self-interest. Giving notice to his key contractors put his business at risk of receiving lower quality because the contractors now viewed the account as temporary and faced intense pressure to shift their business to new manufacturers. Yet the manufacturer notified his close contractors with a personal visit to their shops (something 
he hadn't done in years, even though he spoke with them frequently on the phone) because their embedded tie led him to believe that they would not lower their quality and obliged him to help them adapt to the loss of his business. "My personal visit shows that we are sensitive to their special needs," he said. In keeping with this interpretation, a contractor of this manufacturer reported independently that the manufacturer's trusting gesture affirmed their mutual commitment, which he repaid by maintaining quality. Moreover, he said that his maintenance of quality was not due to a concern for his reputation because other firms were likely to view the "deserting" manufacturer, not him, as betraying trust.

This case is illustrative because neoclassical, game, and transactioncost economic theories all argue that the cooperative behaviors I attribute to embeddedness can be explained simply by the self-interested pursuit of economic ends: Cooperation persists only as long as the narrow economic returns of cooperation exceed those of selfish individual behavior. The decisive indicator of selfish motives is that players defect from cooperative to self-interested behavior when the "endgame" occurs--when they know the "repeated game" is ending and therefore stop cooperating because cooperation yields lower payoffs than self-interested action (Simon 1991). Contrary to this argument, the above case demonstrates that once embedded relationships form, firms continue to cooperate even after the endgame obtains. In other cases I observed firms sending work to network partners who needed it to survive in the short run to help their network partners survive, even though the same work could have been sent to another shop that offered immediate volume discounts. One CEO said, "I tell them that in two weeks I won't have much work. You better start to find other work. (At other times) when they are not so busy, we try to find work...for our key contractors. We will put a dress into work...to keep the contractor going... Where we put work 
depends...on (who) needs to work (to survive)." Another CEO, summing up the effects of embeddedness on organizational performance, said, "Win-win situations [her term for embedded ties] definitely help firms survive." These cases are inconsistent with standard economic assumptions about social structure and economic action because the manufacturer could not predict that the distressed contractor would rebound; yet if he wished, he could get immediate volume discounts from another contractor in the market. These actions make sense, however, from the perspective of structural embeddedness: They enhance organizational survival through resource sharing and commitment that is born from a concern for the finding positive-sum outcomes and supported by embedded ties.

Structuration. The significant structural shift due to the constitution of embedded ties is that the original market of impersonal transactions becomes concentrated and exclusive between sets of partners, forming networks of organizations. This structural shift is significant because it links together multiple dyads into a network composed of embedded ties. One CEO explained how the formation of a network indicates and reinforces embeddedness: "Of course [opportunism] can be a problem, but do you think that I would ever have made such a close relationship with this guy over so many years if I thought he would screw me if he had a chance? That's why he has so much business. I can trust him." Other manufacturers said, "Close relationships come from giving a lot of business, else it's up for grabs." "I have become really good friends with manufacturers; the friendships come with the business."

In contrast, arm's-length ties had a counter effect on structuration. Since the threat of withdrawal could be used to exploit bargaining power, they were viewed as signaling distrust. As one CEO explained, "It's still business 
and you need a profit to survive. So what makes you important? You can't just depend on friendship. The low end of the market has too many contractors and their production is too big. If you are the last guy [the contractor a manufacturer depends on least], you get kicked out first when business slows." This statement demonstrates a recurring theme: Embeddedness cannot be developed in atomistic relationships. It may require the type of smallnumbers bargaining situations that, according to transaction cost theory, produces opportunism and inefficiency rather than competitive advantages. In summary these ethnographic findings in conjunction with existing theory suggest that embeddedness is a unique logic of exchange. Whereas neoclassical accounts focus predominantly on asocial and price-determined allocative mechanisms of exchange (Coase 1991), the structural embeddedness approach emphasizes how social networks achieve outcomes that may equal or surpass market alternatives. In this framework, the unit of analysis is the nature of the social relationship between and among exchange partners. Embedded ties promote, and enable the greatest access to, certain kinds of exchanges that are particularly beneficial for reducing monitoring costs, quickening decision making, and enhancing organizational learning and adaptation. These benefits not only accrue to the individual firms of a network connected via embedded ties, but to the network as a whole, which also acts as a social boundary of demarcation around these unique resources. Consequently, knowledge of a firm's embeddedness: Its position in a network, the quality of its ties to network partners, and the structure of the network, provide the basis on which to make predictions about organizational performance and capability, both positive and negative. 
In the above discussion I suggested a series of predictions regarding embeddedness and network ties. I develop some of these propositions below, accenting the association between (1) embeddedness and production market structure and (2) embeddedness and organization performance. As stated earlier, my aim is to illustrate the main implications of the framework and to show its plausibility rather than to render a definitive proof (cf Uzzi 1997).

\section{Networks, Embeddedness, and Production Market Structure}

Several theories argue that the most competitive form of organization will predominate in a distribution of similar organizations (Hannan and Freeman 1989; North 1990). According to market theory, the idealized efficient market structure should be characterized by atomized collections of independent firms linked through arm's-length ties, especially when there are many buyers and sellers and products are non-specific. Contrary to this argument, my fieldwork suggests that embedded networks of organizations achieve certain competitive advantages over market arrangements even in production markets with many substitutable shops and low search and start-up costs. As a result, it implies that production markets should be characterized by networks of organizations rather than by loose dispersions of unitary firms. This argument is also consistent with White's (1981) theory of markets. In his theory, dense networks of social ties exist for reasons that complement my own. Markets are primarily viewed not as price determining mechanisms, but as devices that link firms through signalling and direct communication because most firms have the ability to match their production schedules to their production costs with greater accuracy than they can forecast matches between supply and demand based on abstract price information: "Markets are tangible cliques of producers watching each other. Pressure from the buyer side creates a mirror in which producers see themselves, not consumers" (White 
1981: 543). Consequently, successful producers best manage production by examining the prior performance of their collaborators and competitors, rather than market data. Thus we should observe market structures that gravitate toward dense networks of ties, rather than idealized atomization. This suggests

H1: Competitive production markets will be characterized by embedded networks of organizations rather than by an atomistic mass of discrete firms.

Network Effects and Economic Performance: A Focus on Organization Survival The basic premise of the structural embeddedness approach--that embeddedness is an opportunity structure--suggests that two conditions specify the relationship between embeddedness and economic performance. The first concerns how a firm is linked to its network. This condition determines an organization's access to the benefits circulating in the network. The second condition concerns the level of benefits apportioned in the network and is set by the kind of network structure to which the focal firm is tied.

The structural embeddedness argument suggests that embedded ties provide the greatest access to the benefits circulating in the network. Because of the high level of information exchange, trust, and joint problem-solving arrangements that characterize embedded ties, firms can most rapidly gain entry into, and capitalize on, the opportunities afforded by the network. In contrast, arm's-length ties provide few social or economic incentives on which to construct these benefits or induce network partners to share them. This suggests

H2: Organizations tied to network partners by embedded, as opposed to arm's-length, ties increase their probability of survival. 
This logic can also be extended to business group networks that are linked through embedded ties. Business groups are a particular kind of organizational network that tends to be composed of independent firms that are linked by ties of friendship, family, or shared equity, but are not controlled formally by a legal or administrative entity (Granovetter 1994). This form of embeddedness is related to the above, but varies from it in that the firms in the network are not necessarily linked by resource exchanges. Instead family or friendship ties, or voluntary membership, demarcates the network's boundary, which in turn delimits the unique resources available to the members of the network (Portes and Sensenbrenner 1993). As a result, group members are predicted to obtain competitive advantages over firms that lack membership, an argument consistent with Portes and Sensenbrenner's (1993) findings on Cuban entrepreneurs in Miami. This suggests:

H3: Organizations increase their likelihood of survival when linked to a business group network formed around embedded ties.

Hypotheses 2 and 3 describe how a firm should be connected to its network to tap the benefits of embeddedness. Hypothesis 4 shifts the focus to the kind of network that is likely to contain the most benefits and marks a transition toward understanding how the performance benefits of embeddedness can reverse themselves under certain conditions. I conject that, if arm'slength ties become embedded as firms enjoy the benefits of coordination and adaptation, then, once embeddedness increases beyond a certain threshold of intensity, the firms in the network may become sealed off from the market as they begin to trade with a confined set of network partners. When this threshold is reached, the flow of new or innovative information into the network begins to decrease; eventually it is closed off in highly embedded networks because there are few nonredundant links to outside members who 
potentially could introduce new ideas into the network (Burt 1992). Over time, isomorphic processes can also decrease network diversity and increase organizational inertia so that change is difficult and costly for network partners (Hannan and Freeman 1989). For example, Grabher's (1993) study of the decline of the Ruhr steel industry and Glasmeier's (1991) research on the failure of the Swiss watchmaking industry both found that a closed network structure limited the recognition of new and innovative processes and contributed to the decline of firms in these industries. In highly embedded networks, feelings of obligation, friendship, or betrayal may also be so intense that emotions override economic imperatives. Some firms in the network may devote resources at a rate that exceeds their capacity to support themselves or may become governed by negative sentiments that misdirect organizational resources. One CEO explained how overly tight coupling sometimes can create negative outcomes: "Factories are really comfortable doing business with us. They know we're no hit-and-run operation....But if you screw a guy like this (a close tie), he'll stay in business just long enough to get even." Eventually either process leads to a network that is out of step with the environment, and ultimately leads to organization failure.

On the basis of this analysis of the different outcomes of arm's-length and embedded exchange relations, I hypothesize that a theoretic optimum between the countervailing effects of under- and overembeddedness exists when a network is composed of a mixture of arm's-length and embedded ties. On one hand, networks constituted of embedded ties benefit from trust, joint problem solving, and thick information exchange, which enhance coordination and resource sharing. On the other hand, networks composed of arm's-length ties have wide access to information circulating in the market and an enlarged ability to test new trading partners. This suggests that networks consisting 
of a mix of arm's-length and embedded ties have the greatest adaptive capacity because embedded ties facilitate coordination and resource pooling, while arm's-length ties prevent the network's insulation from market imperatives. By this argument,

H4: The probability of organization survival increases as the network with which the focal firm transacts tends toward an integrated network of embedded and arm's-length ties; conversely, the probability of organizational survival decreases as the network with which the focal firm transacts tends toward (1) all arm's-length ties or (2) all embedded ties.

The above hypotheses suggest that a network effect exists at two levels. According to Hypotheses 2 and 3, a firm increases its access to network opportunities via embedded ties. In this case, a firm does best when its exchanges are coupled with a few network partners via embedded ties rather than being spread out among many firms via arm's-length ties, as market theory prescribes. Hypothesis 4 argues that the opportunities available to an organization are established by the composition of ties making up the network with which it transacts. In this case, a focal firm does best when its network partners maintain an integrated mix of arm's-length and embedded ties with their network partners. Thus a firm's performance peaks when it is linked by embedded ties (Hypotheses 2 and 3) to an integrated network composed of both embedded and arm's-length ties (Hypothesis 4).

\section{DATA AND METHODS}

Data on the network ties among all better dress apparel firms in the New York apparel economy were obtained from the International Ladies Garment Workers Union, which keeps records on the volume of exchanges between contractors and manufacturers (see Uzzi 1993). The data describe (1) firm-to-firm resource exchanges, (2) business group membership, and (3) a company's product lines, 
age, size of employment, and location. The data on resource exchange and social tie networks cover the full network of relations for each firm in this economy (e.g., the proportion of work that each firm "sends" and "receives" to and from its network partners and whether firms are linked by family, friendship, or shareholdings). The union collects these data in order to calculate a worker's union dues, which are paid by the employer on the basis of the amount of work done in the employer's shop. Records are updated by union examiners, who audit books on-site and verify plant closures. Network exchange data was available from the beginning of the second quarter of 1990 to the end of 1991 for union firms only and did not specify the date for individual transactions-it was only known that a specific percentage of firm's exchanges was due to each of its network partner. Over eighty percent of New York's better dress firms are unionized; nonunion firms typically are illegal shops evading taxes and labor laws (Waldinger 1989). Although the sampling procedure and the unique nature of these network data offer many advantages, as noted above, the relatively short and timeinvariant nature of the numerical data pose a problem similar to that of other network studies (Burt 1992; McPherson, Popielarz, and Drobnic 1992). One issue concerns the modeling of the causes of failure before the year of observation because it is likely that the causes of survival are a function of characteristics that existed before that year. Multiple observation points would permit stronger causal inferences. In the absence of such data, several aspects of this analysis help to minimize the effects of this problem: I include controls for the main predictors of survival, which have been found to capture the effects of prior organization characteristics. Principal among these are organizational age, size, and geographic location. Insofar as these variables capture the effects of learning, access to capital, slack resources, 
and better-trained management (Hannan and Freeman 1989), they help to control for the pre-1991 causes of failure.

These data also preclude the complete determination of the direction of causality. If a positive association is found between embeddedness and survival, as predicted, one cannot rule out, on the basis of the numerical data alone, that embeddedness is a consequence rather than an antecedent of survival. It could be that surviving firms have embedded ties because they are regarded as economically reliable enough to gain business, not because embedded ties help them to adapt.

The analysis tries to overcome this causal ambiguity in several ways. First, the ethnographic data help to untangle competing interpretations of the direction of causality. Because interviewees have experienced a history of relationships between embeddedness and outcomes, they provide data on the degree to which embeddedness causes, or is due to, performance (Miles and Huberman 1984). Furthermore, if the ethnographic data and the statistical results converge, such convergence gives additional support to my interpretation of the findings (Jick 1979). Second, the possibility that the results spuriously reflect economic stability rather than the social determinants of survival is reduced insofar as the age and/or size of an organization measures stability (Hannan and Freeman 1989). Third, my argument turns on the distribution of exchanges, not on the absolute volume of a firm's business. Thus the total volume of a firm's business is immaterial in distinguishing whether a firm is an economically reliable partner; what matters is how it distributes its business among its network ties. Finally, as McPherson et al. (1992) have argued, this problem is part of a general class of problems that introduces measurement error into the network variables. However, since measurement error usually attenuates estimates, it results in a conservative test of hypotheses. Thus, because the goal of this 
study is to demonstrate the plausibility of the formulation rather than to claim definitive tests, the combining of qualitative analysis and conservative quantitative tests supplies a reasonable foundation for analysis. ${ }^{2}$

Dependent Variable

I modeled a firm's likelihood of failure during the period 1991 using logit analysis. If a firm failed between January 1, 1991 and December 31,1991 it was coded as 1; 0 , otherwise. The logit analysis models the survival likelihood of contractor firms only because only eight of 89 manufacturers closed in 1991; a sample size that is too small to permit estimation of reliable maximum-likelihood coefficients (Aldrich and Nelson 1990). One hundred and twenty-five, or 25 per cent, of the 484 contractors failed in 1991, a typical failure rate for businesses of this size in highly competitive industries (Brüderl, Preisendorfer, and Ziegler, 1992; NYS Department of Labor Files). The absence of data for five firms reduced the sample to 479. Union examiners physically identify firms that close purposely in order to exploit tax laws and then reopen under a new name with basically the same personnel. I found no firms of this type.

Independent Variables

2 The premise of convergence is that the strengths of one method offset the weaknesses of another. Convergence between qualitative and quantitative methods occurs when the two methods yield systematically similar results; it is most effective when qualitative methods are used to build theory and interpret statistical findings, as done here. Thus, although there are no statistical tests to prove convergence, it works by demonstrating that a model is a accurate representation of the data in the same way as independent variables explain only part of the variance, and just as psychometric methods 
The degree to which a firm uses embedded ties to link to its network was measured with the variable first-order network coupling. This is calculated by summing the squared proportion of work done by a contractor for each of its manufacturers. I chose this measure for several reasons. First, it had strong face validity among interviewees. As shown by typical responses to questions about the relationship between the distribution of exchanges and embeddedness, interviewees believed that concentrated exchanges reflected "special relationships." Second, in a direct attempt to operationalize embeddedness, I asked interviewees "How would you determine if a company has a 'special relationship' with another firm if it were impossible to ask the company representative directly?" Respondents consistently answered that firms which concentrate their exchanges with a few trading partners rather than spreading out their exchanges in small parcels among many partners were likely to have embedded ties with those firms. Third, the measure has precedents in the literature (Baker 1990).

First Order Network Coupling $=\sum_{j}^{n}{ }_{=}^{m} \quad P^{2}{ }_{i j}$

The term $n_{m}$ equals the number of manufacturers that contractor $i$ works for; $P_{i j}$ is the percentage of contractor i's output that is sent to manufacturer $j$. A contractor in a first-order network of size $n_{m}=3$ which sends 40 percent of its output to manufacturer 1, 50 percent to manufacturer 2, and 10 percent to manufacturer 3 over the observation period has a first-order network coupling value of $(.40)^{2}+(.50)^{2}+(.10)^{2}=.42$. The index approaches 1.0 as the focal firm's transactions become concentrated in a few relationships. At its limit of 1.0, a contractor does 100 per cent of its work for one manufacturer.

use rules of thumb to choose among alternative models of data structure (Jick 1979). 
Conversely, when the value tends toward zero, the contractor spreads out its work in small parcels to many manufacturers; that is, it uses arm's-length ties to transact with its manufacturer network. I use the sum $P^{2}{ }_{i j}$ because it captures the idea of embeddedness as a network concept more fully than does the value of the highest resource dependence tie between a contractor and its manufacturers (Baker 1990).

Social capital embeddedness is an indicator variable coded 1 if a contractor has network ties to a business group (defined above); 0 otherwise. In agreement with Granovetter's (1994) definition, interviews with CEOs of business group firms and with union officials verified that business groups in this industry are enduring collections of legally independent firms which form around CEOs who are kin or who were colleagues from previous jobs. Unionized firms must disclose their membership in a business group if they participate in or have family or equity ties to a business group. The data do not specify the kind of tie(s), but only indicate that a tie of at least one of these types exists between the focal firm and a group. It is important to acknowledge that contractors that are business group members are not vertically integrated suppliers in this sample, but are independent firms that normally work for several manufacturers in or outside the business group. (The $r^{2}$ between first-order network coupling and social capital embeddedness is $\cong$ .09. Interview and union data also indicated that no vertically integrated dress firms currently exist). Thus, this variable most closely operationalizes Portes and Sensenbrenner's (1993) construct of social capital embeddedness, not vertical integration. Second-order network coupling measures the degree to which a focal firm's network partners maintain arm's-length or embedded ties with their 
network partners. The index is calculated in two steps. First, $D^{2}{ }_{j i}$ the percentage of manufacturer's total inputs that is received by contractor, Second Order Network Coupling $=\frac{\sum_{j=1}^{n_{m}} Q_{j}}{n_{m}} \quad Q_{i} \quad Q_{j}=\sum_{i=1}^{n_{s}} D_{j i}^{2} \quad$ (3) is squared and summed over $n_{s}$, the total number of contractors that work for manufacturer, to equal $Q_{j} \cdot Q_{j}$ varies between 0 and 1 : A value of 1 means that 100 percent of manufacturer j's work is done by one contractor and a value near 0 means that manufacturer j spreads out its work among a large network of contractors, each of which receives a small portion of manufacturer j's total work. Second, with equation 2, the value of $Q_{j}$ for manufacturer $j$ is summed and then divided by $n_{m}$, the number of manufacturers in contractor i's network. When the value of this index is low, the network of manufacturers with which the contractor transacts use, on average, arm's-length ties with their contractors; that is, they spread out their work among a large network of contractors, each of which accounts for a small percentage of the manufacturer's total business. When the value of this index is high, the network to which a contractor is tied is composed of manufacturers that use embedded ties to transact with their contractors; they concentrate their business in a select group of contractors. When the value of the index is at a medium level, the contractor transacts with an integrated network--one that is composed of a mix of arm's-length and embedded ties.

Control Variables

Network Size is a control for the size of the focal firm's network; it equals the number of manufacturers a contractor worked for during the observation 
period. Network Centrality is controlled via a number of indirect ties (Knoke and Burt 1983) and equals the number of indirect ties of the focal contractor; for example, a contractor who works for two manufacturers, each of which sends work to three contractors, has six indirect ties, less duplicate firms. Organization Age equals the number of years a contractor has been in business and is based on the date when the firm was organized. Union officials estimate that most firms unionize within one or two years after start-up. This measure, therefore, is consistent with ecological and economic research that uses license registration dates (dates that normally lag one to two years behind the start of operations) to estimate age (Brüderl et al. 1992). Organization Size equals the number of unionized workers in the contractor's factory during 1991. No sales data are available. Finally, ecological and economic models find that organizational generalism, specialism, and region (controls for differences in production costs and in local niche competition) affect survival (Hannan and Freeman 1989). Generalist is a binary variable equal to 1 if a contractor makes multiple products (e.g., dresses and pants); 0 otherwise. I created an indicator variable for firms located in Manhattan, Brooklyn/the Bronx, and outside New York (Queens, NJ, PA) based on cost differences in these regions.

\section{RESULTS}

\section{Industrial Market Structure}

The expected pattern of exchange relationships in an atomistic market is that of an expansive, undifferentiated macronetwork: Firms parcel out their orders among many exchange partners, forcing them to compete vigorously for business (White 1981; Baker 1990). Using this expectation to analyze the structure of production markets, I found mixed support for Hypothesis 1 . In this economy, 
some firms organize as diffuse collections of atomistic actors while others organize in networks.

Insert Figure 1 about here

Figure 1 shows the cumulative distribution of trading ties for all better dress firms in the New York regional economy from the second quarter of 1990 to the end of 1991. The total business of a firm consists of four or five distinct production runs per year (fall, winter, spring, summer, and resort seasons). At each production run a firm decides whether to stay with the exchange partner of the last production run or to switch to a new one. Firms can allot their transactions among many network partners, each of which receives a small percentage of the focal firm's business, or can concentrate their transactions with a few trading partners, each of which receives a large percentage of the focal firm's business. A conservative reading of these patterns suggests that a firm which sends more than 20-25 per cent of its business to an exchange partner (one year's total business divided by five production runs) maintains a "special" or embedded tie; otherwise it represents an arm's-length tie. This interpretation is consistent with the structure of production in this industry and with interview data reported above which revealed that it was unlikely for a firm to have concentrated exchanges with another firm unless an embedded tie existed.

Figure 1 suggests that the market structure of the garment economy is composed mostly of arm's-length ties. The solid line represents how 91 manufacturers distributed their total business among 504 contractors $(\mathrm{N}=$ 1,093 dyadic exchange ties); the dashed line represents the same relationships, but shows how 504 contractors distributed their business among 91 manufacturers. The horizontal axis is the percentage of work sent per tie 
to an exchange partner; the vertical axis is the cumulative percentage of ties. These data show that firms appear to spread out their business among many exchange partners rather than concentrating their ties with a few firms. The solid "manufacturer" line shows that more than 80 per cent of all exchanges from manufacturers to contractors are for 10 per cent or less of a manufacturer's total business; correspondingly, only a few ties account for 20 per cent or more of a firm's total business. The dashed "contractor" line indicates a similar but less pronounced pattern: About 55 per cent of all exchanges from contractors to manufacturers are for 10 per cent or less of a contractor's total business, but fully 25 per cent of the contractor-tomanufacturer ties account for 20 per cent or more of a contractor's total business, which includes a subset of about 10 per cent of the contractors that send 100 per cent of their business to one manufacturer. Thus, in keeping with neoclassical theory, this reading of the data suggests that the market structure of a competitive industry is a diffuse collection of discrete organizations which maintain arm's-length ties with one another.

The above representation, however, may underestimate the importance of embedded ties if firms tend to use one or a few exchange partners for a large percentage of their business and then spread the remainder among many lowlevel ties. For example, if firms typically distribute their business among 15 exchange partners with two of these partners each accounting for 25 per cent of the business and the other 13 partners evenly dividing the other 50 per cent of the business, then the aggregate distribution of ties would suggest a dispersed market structure even though close ties with two exchange partners reflect a disproportionately large part of the transactions. This situation would produce an aggregate distribution composed of many arm'slength exchanges and only a few concentrated exchanges, as depicted in Figure 1. Thus, if we examine instead the distribution of principal exchange ties 
(i.e., the exchange ties accounting for the highest percentage of a firm's business), we obtain an alternative measure of market structure. If this distribution shows that firms concentrate their exchanges with one or a few network partners, it offers evidence for the presence of embeddedness.

Insert Figure 2 about here

Figure 2 displays the distribution of principal ties and suggests that embeddedness is an important component of interfirm exchanges for some companies. The solid line represents the cumulative distribution of principal trading ties from 91 manufacturers to 504 contractors ( $=91$ exchange ties); the dashed line represents the cumulative distribution of principal trading ties from 504 contractors to 91 manufacturers ( $N=504$ exchange ties). The horizontal axis is the percentage of work sent to each firm's largest trading partner; the vertical axis is the cumulative percentage of principal ties across all firms. The graph shows that a significant set of firms concentrate their relationships with a few trading partners. The solid "manufacturer" line indicates that about 50 per cent of the manufacturers send 25 per cent or more of their business to a principal contractor. The dashed "contractor" line shows a similar but more prominent pattern of embeddedness: 15 per cent of all contractors send 100 per cent of their output to one manufacturer; about 45 per cent send 50 per cent or more of their output to one manufacturer. These results suggest that although most firms use arm's-length ties routinely, a major portion of their business is managed through the use embedded ties - underscoring their importance.

Analysis of the network size of firms further supports the embeddedness argument that market structure consists of more long-term network ties than would be predicted under neoclassical or transaction cost theory, although 
again, the data suggest a dual pattern of market structure in this economy: Some firms appear to manage their relationships with arm's-length ties, while others use embedded ties. In this sample, an examination of the distribution of network ties shows that 25 per cent of the manufacturers have tightly knit networks composed of five or fewer exchange partners on average; 30 per cent have a network size of five to twelve; and about 40 per cent maintain large, expansive networks of 20 or more contractors. Similarly, about 35 per cent of the contractors have tightly knit networks of three manufacturers or fewer; about 45 per cent have an average network size of four to eight manufacturers; and about 20 per cent have large networks of nine exchange partners or more. This suggests that some firms use embedded ties and organize in networks, whereas others use arm's-length ties and allot their transactions among a diffuse set of exchange partners.

Therefore, this economy provides evidence for a more complex structure than is suggested either prevailing atomistic or embeddedness accounts (White 1981). In agreement with neoclassical theory, some firms transact using principally arm's-length ties; other firms, in keeping with embeddedness, appear to form tangible networks of producers linked by embedded ties.

Organization Performance: Multivariate Analyses

Table 1 presents the results of eight models that estimate the failure probability of a contractor in 1991. The log-likelihood value across the models shows that embeddedness variables significantly improve the fit of the baseline control models (Models 1 through 4) at the $p<.05$ level when added as individual variables (Models 5 through 7) or as a block (Model 4 versus Model 8). 
In agreement with Hypothesis 2, Models 5 and 8 show that increasing first-order network coupling is associated with a lower probability of failure. This result suggests that a contractor's probability of failure decreases when it uses embedded ties and increases when it spreads its business among many manufacturers via arm's-length ties. Figure 3 illustrates this effect while holding the other statistically significant covariates in Model 8 at their mean values. Firms with a low level of first-order network coupling fail at a predicted rate of 27 per cent. Firms with a high level of first-order network coupling, fail at a rate of 14 per cent, suggesting that embeddedness decreases the likelihood of failure for the average firm by 50 per cent. ${ }^{3}$

In keeping with Hypothesis 3, Model 6 and Model 8 show that social capital embeddedness has a negative and significant effect on the likelihood of failure. This finding is important for two reasons. First, the positive association between Portes and Sensenbrenner's (1993) concept of social capital embeddedness and structural embeddedness suggests that different operationalizations of embeddedness correlate in the same way with

3 Only the sign and statistical significance of logit coefficients are directly interpretable. Equation 4 specifies how to find the predicted probability of failure over the empirically observed range of a continuous independent variable while holding the other significant covariates at their sample means: (1) Multiply the sample mean of each significant covariate in the equation by its logit coefficient; (2) multiply the empirically observed range of values of the independent variable of interest by its logit coefficient; (3) sum the products; (4) exponentiate that sum to obtain the numerator; and (5) divide the numerator by unity plus the numerator to calculate the continuous effect of the independent variable of interest (i.e., the variable on the $x$-axis) on the change in probability of failure while holding the other covariates at the their sample means (Roncek 1991). 
performance, adding support to the validity of the operationalizations. Second, although the social capital embeddedness measure contains some equity ties, it suggests, in line with Granovetter (1994), that socially founded business ties affect organization outcomes positively in the absence of direct material transactions between firms or administrative fiat.

Models 7 and 8 show that the results for second-order network coupling and second-order network coupling squared agree with Hypothesis 4 . The linear coefficient is significant and negative; the squared coefficient is significant and positive. These coefficients jointly suggest that contractors which transact with low-embedded or highly embedded networks have an increasing likelihood of failure, while contractors which transact with moderately embedded networks have a decreasing likelihood of failure.

Insert Figure 4 about here

These results are illustrated in Figure 4. The horizontal axis shows the observed range of values of the second-order network coupling variable; the vertical axis shows the probability of failure when the statistically significant covariates are at their sample mean values. The right- and lefthand tails of the U-shaped curve illustrate that a contractor's probability of failure rises when it transacts with a network of manufacturers who maintain increasingly arm's-length ties (the left-hand tail) or increasingly embedded ties (the right-hand tail) with their other contractors. In contrast, the odds of failure decrease when contractors transact with manufacturers who maintain an integrated network of arm's-length and embedded ties with their other contractors, as reflected in the area around the trough of the curve. ${ }^{4}$ 


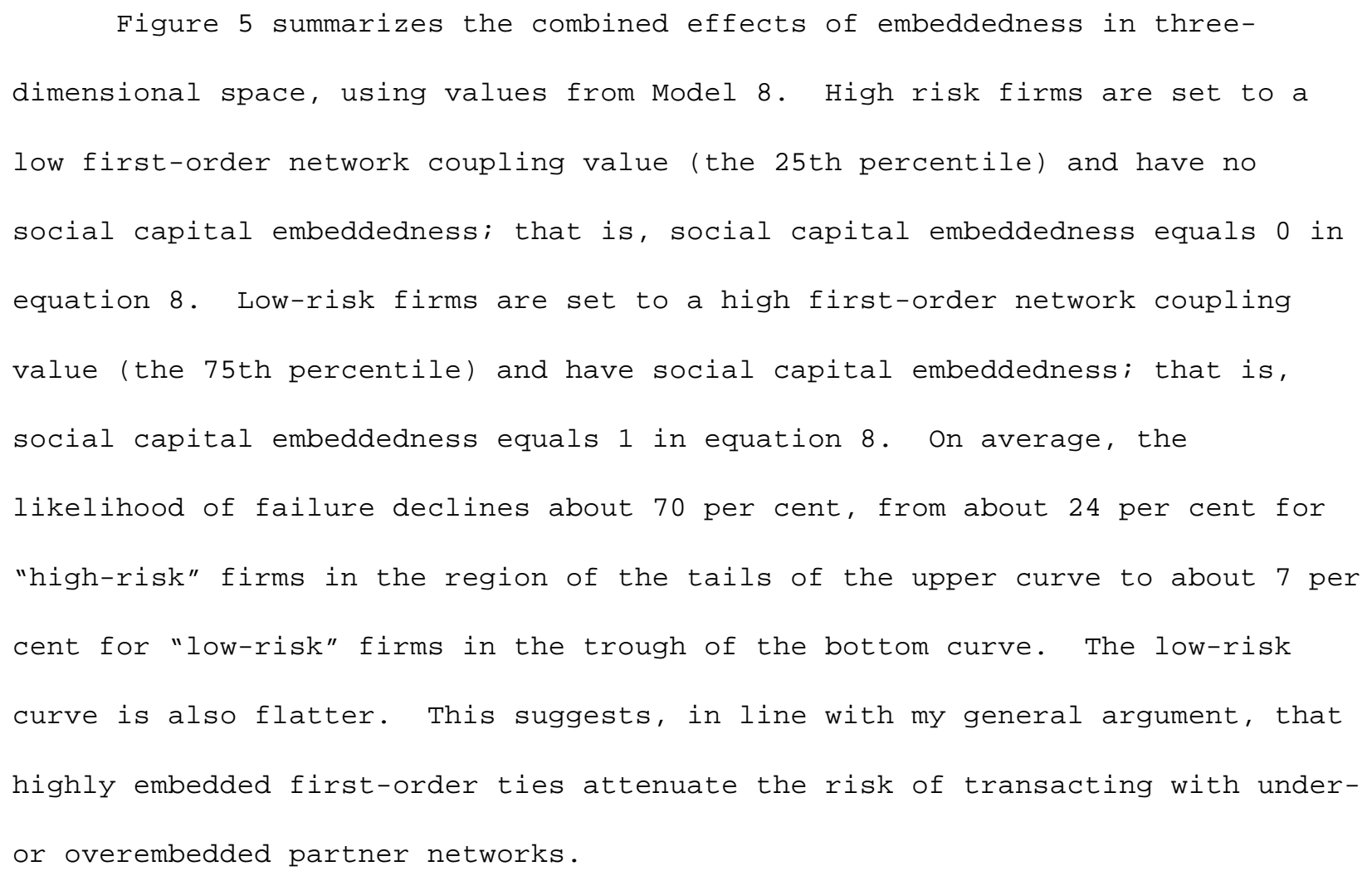

\section{DISCUSSION}

In summary, this research suggests that embeddedness is a logic of exchange which shapes motives and expectations and promotes coordinated adaptation. This logic is unique in that actors do not selfishly pursue immediate gains, but concentrate on cultivating long-term cooperative relationships that have both individual and collective level benefits for learning, risk-sharing, investment, and speeding products to market. These actions and motives are themselves not assumed to be due to the hard-wired orientation of economic

\footnotetext{
4 A post hoc analysis of failed contractors on the right-hand tail of the Ushaped curve showed that their failure was unrelated to the eight manufacturers that went out of business in 1991.
} 
actors or conformity to abstract norms, but to the emergent properties of concrete network relationships. As such issues of self-interest maximization, generalized reputation, and repeated-gaming fade into the background while issues of how social relations promote thick information exchange, rapid and heuristic decision making, and the search for positive-sum outcomes take the fore. In this logic, the network acts as a social boundary of demarcation around opportunities which are assembled from the embedded ties that define membership and enrich the network. An actor's level of embeddedness and attendant performance capabilities depend on the type of ties it uses to connect to its network partners as well as the type of ties used by firms in its network; networks composed of arm's-length ties have low embeddedness, while networks composed of embedded ties have high embeddedness. The outcomes of embeddedness are not unconditionally beneficial however, since embeddedness can paradoxically reduce adaptive capacity under certain conditions.

These conclusions are built on both fieldwork and statistical analyses. The fieldwork suggests that arm's-length and embedded ties are distinct forms of exchange and that embedded ties can produce competitive advantages which are difficult to emulate with arm's-length ties. The fieldwork also suggests that embedded ties develop through stages which begins when existing embedded ties match up new exchange partners. In such cases, go-betweens with embedded ties to actors previously unknown to one another prime the relationship between those newly introduced actors for embeddedness by setting expectations for trust and reciprocity and by equipping it with resources that are "rolled over" from the go-between's existing embedded tie to one of the new network partners. Thus, although embeddedness may arise from both material and social exchange; once formed, it shapes transacting in ways that are not easily explained by the transparent economic factors at hand. 
These findings suggest that a greater understanding of go-betweens, their ability to form, permeate, and stretch the boundaries of social systems, and the conditions under which they can transfer expectations and opportunities of existing embedded ties to new market relationships seems critical for our knowledge of how embeddedness operates. Similarly, future research might continue to approach network analysis with a view that capitalizes on the tools of structural analysis, while acknowledging robust human agency (Emirbayer and Goodwin 1994), since this combined use of ethnography and statistical analysis shows that network models are effectively enhanced by, and consistent with, detailed accounts of how social relations affect economic action.

The statistical analysis suggests that the ethnographic results are generalizable in two ways. First, the distribution of organizational forms found in this sample suggests that industries are complex structures composed of multiple, simultaneously coexisting modes of organizing rather than unitary structures consisting wholly of either markets, hierarchies, or networks. This result has implications for the sociology of markets and organizations, as well as the study of competing strategies of economic behavior. If firms choose between embedded and arm's-length competitive strategies, these results raise significant queries as to what determines the choice of a strategy and under what conditions a particular strategy creates individual firm and society wide benefits. Perhaps more important, the results suggest that embeddedness increases economic effectiveness along a number of dimensions which are crucial to competitiveness in a global economy-organizational learning, risk-sharing, and speed-to-market--perhaps underscoring the growing importance of embeddedness as a logic of economic exchange (Powell 1990$)$. Embeddedness, however, yields positive returns only up to a threshold point. Once this threshold is crossed, returns from embeddedness become 
negative. This process appears to be governed by two principal components. The first concerns how a firm links to its network partners. Firms that connect to their networks by embedded ties have greater chances of survival than firms that connect to their networks via arm's-length ties. The second component concerns the kind of network to which a firm links. In this case, a paradox appears: Optimal networks are not composed of either all embedded ties or all arm's-length ties, but integrate the two. A crucial implication is that embedded networks offer a competitive form of organizing but possess their own pitfalls because an actor's adaptive capacity is determined by a web of ties, some of which lie beyond his or her direct influence. Thus a firm's structural location although not fully constraining, can significantly blind it to the important effects of the larger network structure, namely its contacts' contacts.

As pointed out earlier, although these data offer many benefits, the short time frame of the quantitative data argue for a modest interpretation of the statistical results. For example, one alternative interpretation of the results is that the association between embeddedness and survival reflects a correlation between large, stable orders and survival, not the effect of social ties on survival. Given the research design however, this alternative reading of the results seems unlikely for several reasons. First, controlling for age, a prime indicator of economic stability (Hannan and Freeman 1989), does not lessen the embeddedness effect; this fact provides evidence that economic stability does not confound the association between embeddedness and survival. Second, the effect of embeddedness over firm size and network size variables--two controls for order size/capacity--suggests that the embeddedness effects are net of an association between order size and survival. Third, because order size is controlled, my interpretation is further supported because it appears that the important factor is how social 
ties are distributed across a firm's total business, not whether a firm's order sizes are large or small in an absolute sense. Fourth, given that the ties of a firm's partners matter (i.e., second-order network coupling), it is difficult to argue that exchange intensity indicates the effect of order size because alternative approaches offer no explanation for the association between these kinds of network effects and performance. Finally, as shown above, respondents felt that embedded ties were indicated by concentrated exchange networks. Thus, these results are not meant to suggest that stable, large orders are inconsequential; rather, they support the conclusion that vital, intensive exchanges results from, and are sustained by, embeddedness. ${ }^{5}$ Future longitudinal research is needed on the above issues and to show how ethnicity, organization size, and the fashion sensitivity of markets condition the function and origin of network forms. Such research seems promising and important for specifying the boundary conditions under which these findings hold. For example, the small number of employees in these firms and the personal nature of ties may be especially fertile ground for embeddedness. Research on large Japanese firms, however, shows that personal attachments can successfully manage interfirm ties (Gerlach 1992).

\footnotetext{
5 Although the correspondence between the structural embeddedness approach and resource dependence theory is not quickly summarized, a main difference pertinent to this analysis is that resource dependence theory predicts the opposite of my results--that firms reduce dependence to increase desired outcomes such as autonomy and survival. Thus, if resource dependence theory was operating here, firms with low first order network coupling would have high survival rates. Future research should examine the factors that produce these effects as well as the conditions under which exchange concentration operationalizes embeddedness as opposed to asymmetric power (e.g., Gargiulo 1993).
} 
Consequently, organizing arrangements, not firm size, may be the main

distinction most important to future research.

A broader set of issues concerns how the institutional and cultural underpinnings of society, first examined by Max Weber in The Protestant Ethic and the spirit of Capitalism, construct the values and beliefs that shape economic life. The present research explored how embeddedness arises from relational social and economic ties that foster network closure and extend embeddedness to new social structures. Weber was concerned with explicating a more sweeping but parallel process: How capitalism was supported by a shift from communal, particularistic relationships to arm's-length ties based on self-interest and third-party enforcement. Embeddedness in a modern economy is curious in that it may represent a holdout, or perhaps a return to, communal exchange systems. A reasonable conjecture is that the particularism Weber associated with precapitalist systems is preserved by embeddedness, but at the same time is remade to be more closely align with modern standards of performance. If this conjecture is the case, and if network organization provides a mechanism for creating economic and social benefits that elude analysis predicated on market theory, then it raises the following question: What modern institutions and cultural arrangements need exist if embedded exchange systems are to arise and prosper in a society?

\section{REFERENCES}

Aldrich, John H. and Forrest D Nelson. 1990. Linear Probability, Logit, and Probit Models. New Bury Park, CA: Sage.

Baker, Wayne E. 1990. "Market Networks and Corporate Behavior." American Journal of Sociology 96:589-625. 
Brüderl, Josef, Peter Preisendorfer, and Rolf Ziegler. 1992. "Survival Chances of Newly Founded Business Organizations." American Sociological Review $57: 227-42$.

Burt, Ron. 1992. "Structural Holes: The Social Structure of Competition." Cambridge, MA: Harvard University Press.

Coase, Ronald. 1991. "1991 Nobel Lecture: The Institutional Structure of Production." Stockholm, Sweden: Nobel Foundation.

Crosby, Lawrence A. and Nancy Stephens. 1987. "Effects of Relationship Marketing on Satisfaction, Retention, and Prices in the Life Insurance Industry." Journal of Marketing Research 24:404-11.

DiMaggio, Paul and Walter W. Powell. 1983. "The Iron Cage Revisited." American Sociological Review 48:147-60.

Emirbayer, Mustafa and Jeff Goodwin. 1994. "Network Analysis, Culture, and the Problem of Agency." American Journal of Sociology 99:1411-1454.

Gargiulo, Martin. 1993. "Two-step Leverage: Managing Constraint in Organizational Politics." Administrative Science Quarterly 38:1-19. Gerlach, Michael. 1992. Alliance Capitalism: The Social Organization of Japanese Business. Berkeley, CA: University of California Press. Glasmeier, Amy. 1991. "Technological Discontinuities and Flexible Production: The Case of the Switzerland and the Work Watch Industry." Research Policy $20: 469-85$

Grabher, Gernot. 1993. The Embedded Firm: On the Socioeconomics of Industrial Networks. London: Routledge.

Granovetter, Mark S. 1985. "Economic Action and Social Structure: The Problem of Embeddedness." American Journal of Sociology 91:481-510. 


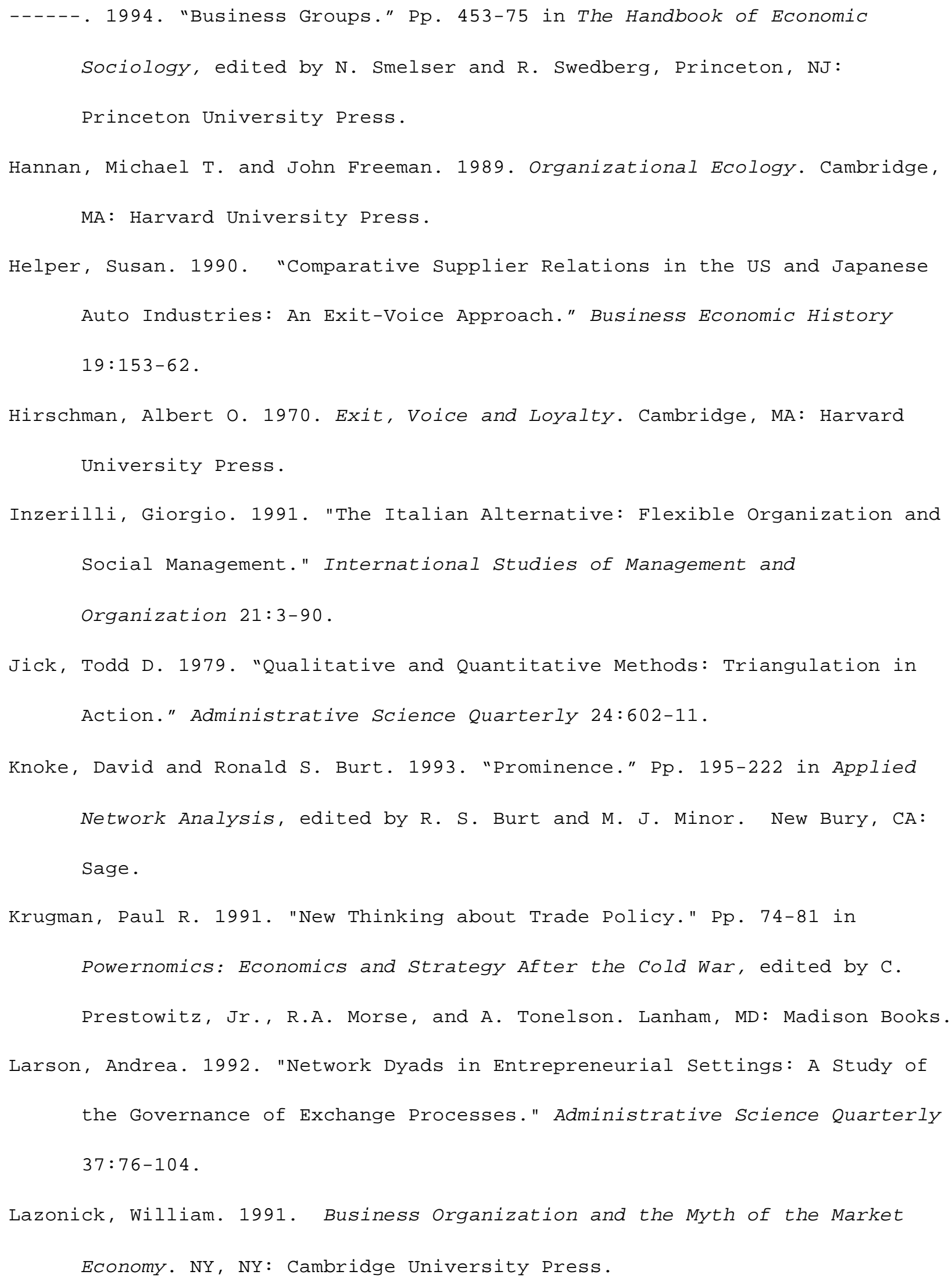




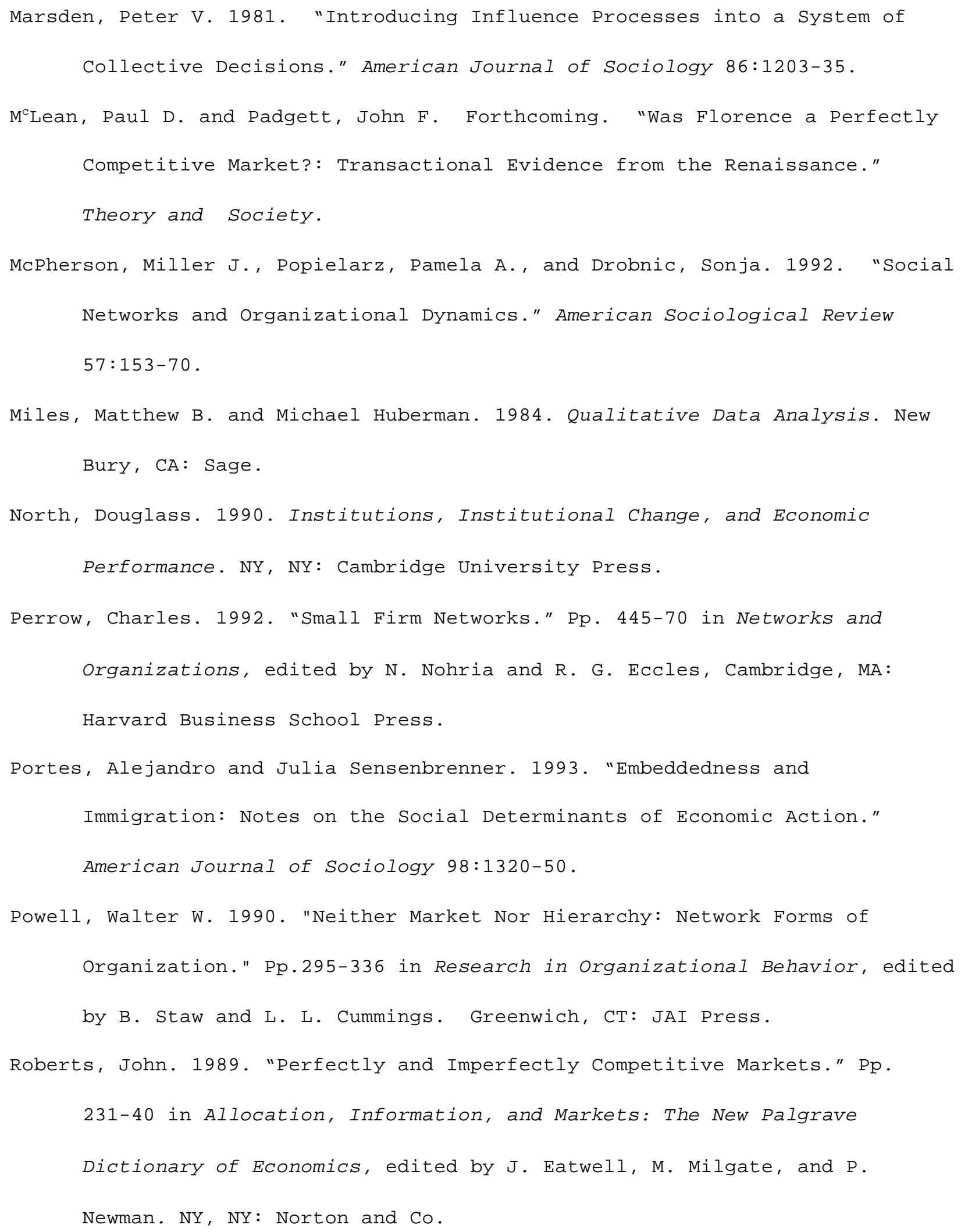


Romo, Frank P. and Michael Schwartz. 1995. "The Structural Embeddedness of Business Decisions: The Migration of Manufacturing Plants in New York State, 1960-1985." American Sociological Review 60:874-907.

Roncek, Dennis W. 1991. "Using Logit Coefficients to Obtain the Effects of Independent Variables on Changes in Probabilities." Social Forces $70: 509-18$

Simon, Herbert A. 1991. "Organizations and Markets." Journal of Economic Perspectives $5: 24-44$.

Smitka, Michael. 1991. Competitive Ties: Subcontracting in the Japanese Automotive Industry. NY, NY: Columbia University Press.

Uzzi, Brian. 1993. "The Dynamics of Interoganizational Networks: Embeddedness and Economic Action." Ph.D. Dissertation, Sociology Department, State University of New York, Stony Brook, NY.

-----. 1996. "Interfirm Networks and the Paradox of Embeddedness: Social Structure and Economic Action in the New York Apparel Industry." Administrative Science Quarterly, forthcoming.

-----. 1997. "A Network Perspective on Organizational Decline and Deindustrialization." International Journal of Sociology and Public Policy, forthcoming.

Waldinger, Roger D. 1989. Through the Eye of the Needle: Immigrants and Enterprise in New York's Garment Trades. New York, NY: New York University Press.

Williamson, Oliver E. 1991. "Comparative Economic Organization: The Analysis of Discrete Structural Alternatives." Administrative Science Quarterly $36: 269-96$ 


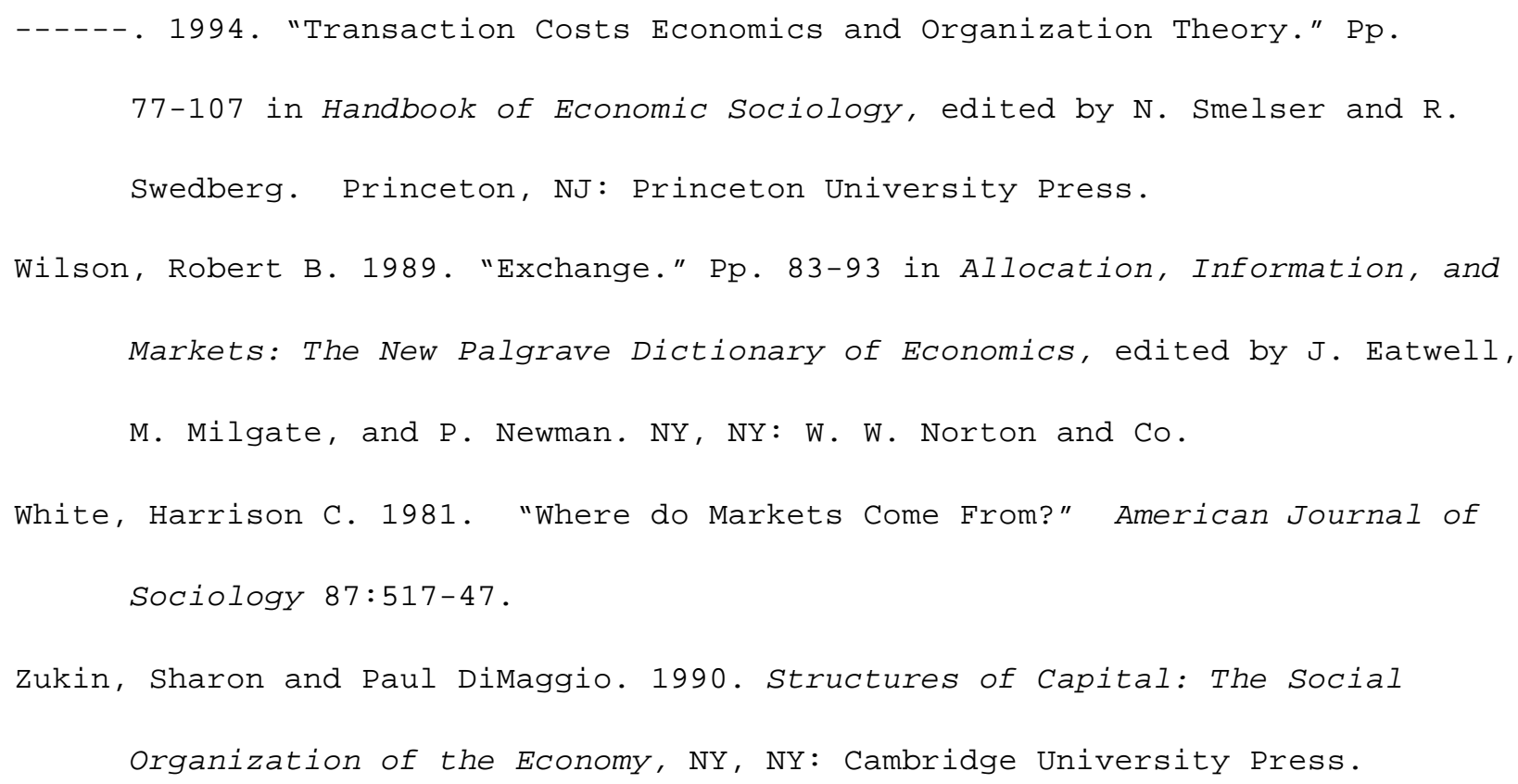

\section{Appendix: Ethnographic Methods and Data}

The ethnographic data are taken from a field study of 23 women's better dress firms (including two pilot studies) in the New York apparel economy, which comprises Manhattan or Seventh Avenue, Chinatown, Queens, Brooklyn, the Bronx, and Western Pennsylvania (see Uzzi 1993). Interfirm relationships in the better dress sector revolve around networks of manufacturers and contractors. Manufacturers are sophisticated assemblers that normally make no part of the garment; instead they design and market it. Manufacturers typically design a "collection" in-house or with freelance designers and then show their collections to retailers, who place orders. Selected designs are produced by a network of contractors: graders, cutters, and sewers in their factories in conjunction with the manufacturer. Networks also include textile mills and converters, which transform textiles into colored and patterned fabric.

CEOs of the above types of firms were contacted by phone; I introduced myself as a student writing a doctoral dissertation on the management practices of Italian and New York garment firms. All CEOs agreed to see me 
within a week of my phone call. The in-depth interviews and tours of plants were conducted between June and December, 1992, with follow-up interviews between October 1993 and November 1993. I spent several days at three firms observing and interviewing executives, production managers, line workers, designers, and their network contacts. These trips enabled me to gather an array of field data on negotiations, problem solving, and exchanges; to ask in-depth questions about different behaviors and relationships; and to compare the accuracy of actors' stated motives and accounts with direct observations. I obtained a register with the name of each firm and CEO in the industry from the International Ladies Garment Worker's Union, which controls work arrangements for more than 90 per cent of the industry (Waldinger 1989). I focused on women's better dresses, a "midscale" subsector of the industry (retail \$80-\$250), to control for economic, market, and technological differences between sectors. In 1992, this sector contained 89 union manufacturers and 484 union contractors. I selected a subgraph of 21 firms from these records according to type of firm, employment size, CEO ethnicity, CEO gender, and location to ensure representativeness of the sample. Data collection and analysis followed Miles and Huberman (1984). I recorded the interviews and ethnographic observations in shorthand in a handsize spiral notebook during interviews and field observations, creating a behavioral record for each type of data. Company records and union files that summarize the key characteristics of the unionized firms in my sample were used to supplement the field data. Twelve of the 23 firms were unionized. The pre-study phase consisted of two pilot interviews that I used to learn how interview materials and self-presentation affected the interviewees' reporting accuracy. Phase 1 revolved around open-ended questions, moderately directive interviews, and field observation. I conducted interviews carefully 
so that concepts such as "risk, small-numbers bargaining, defection," and other economic factors were examined adequately during discussions. Interviews ran no less than two hours, thirty per cent of the CEOs invited me to walk freely around the establishment and to interview and observe employees; 60 per cent invited me to return for a follow-up visit. In Phase 2 I formed an organized interpretation of the data through an iterative process of comparing the data to existing theory and to the emerging framework. First I developed a framework based on extant work in sociology and economics. Then I traveled back and forth between data collection and the framework. I conducted a formal analysis using the "cross-site display table" technique (see Uzzi 1996), which shows the frequency and the weighting of responses across cases with the purpose of documenting the fit of the framework to data sources (Miles and Huberman 1984). As the evidence accumulated, I dropped or revised parts of the framework. Some aspects of the data supported the framework and the current theory; other aspects did not fit the framework, just as independent variables rarely explain all the variance. Phase 3 focused on developing construct validity. I triangulated results using industry experts, union officials, and follow-up interviews. Debriefings did not reveal demand characteristics, inaccurate reporting, or undue response bias. 


\begin{tabular}{|c|c|c|c|c|c|c|c|c|}
\hline Variable & Model 1 & Model 2 & Model 3 & Model 4 & Model 5 & Model 6 & Model 7 & Model 8 \\
\hline \multicolumn{9}{|l|}{ Embeddedness and Network Structure: } \\
\hline 1st-Order Network Coupling & -- & -- & -- & -- & $\begin{array}{l}-1.044++ \\
(-2.54)\end{array}$ & -- & -- & $\begin{array}{l}-0.990++ \\
(-2.37)\end{array}$ \\
\hline Social Capital Embeddedness & -- & -- & -- & -- & -- & $\begin{array}{l}-0.670+ \\
(-1.69)\end{array}$ & -- & $\begin{array}{l}-0.700+ \\
(-1.72)\end{array}$ \\
\hline 2nd-Order Network Coupling & -- & -- & -- & -- & -- & -- & $\begin{array}{l}-7.344+ \\
(-1.96)\end{array}$ & $\begin{array}{l}-6.502+ \\
(-1.70)\end{array}$ \\
\hline 2nd-Order Network Coupling Squared & -- & -- & -- & -- & -- & -- & $\begin{array}{c}13.387+ \\
(2.13)\end{array}$ & $\begin{array}{c}12.529+ \\
(1.94)\end{array}$ \\
\hline \multicolumn{9}{|l|}{ Network Controls: } \\
\hline Network Size & -- & -- & -- & $\begin{array}{r}0.084 \\
(1.12)\end{array}$ & $\begin{array}{l}0.046 \\
(0.60)\end{array}$ & $\begin{array}{r}0.091 \\
(1.21)\end{array}$ & $\begin{array}{l}0.109 \\
(1.43)\end{array}$ & $\begin{array}{r}0.078 \\
(0.99)\end{array}$ \\
\hline Centrality & -- & -- & -- & $\begin{array}{l}-0.003 \\
(-0.93)\end{array}$ & $\begin{array}{c}-0.004 \\
(-0.51)\end{array}$ & $\begin{array}{l}-0.004 \\
(-1.02)\end{array}$ & $\begin{array}{l}-0.005 \\
(-1.30)\end{array}$ & $\begin{array}{l}-0.006 \\
(-1.45)\end{array}$ \\
\hline \multicolumn{9}{|l|}{ Ecological and Economic Controls: } \\
\hline Organizational Age & -- & -- & $\begin{array}{l}-0.047 * \\
(-2.19)\end{array}$ & $\begin{array}{l}-0.052^{*} \\
(-2.35)\end{array}$ & $\begin{array}{l}-0.049 * \\
(-2.22)\end{array}$ & $\begin{array}{l}-0.055^{*} \\
(-2.47)\end{array}$ & $\begin{array}{l}-0.051^{*} \\
(-2.29)\end{array}$ & $\begin{array}{l}-0.053 * * \\
(-2.32)\end{array}$ \\
\hline Organizational Age Squared & -- & -- & $\begin{array}{r}0.000 \\
(1.67)\end{array}$ & $\begin{array}{r}0.000 \\
(1.80)\end{array}$ & $\begin{array}{r}0.000 \\
(1.67)\end{array}$ & $\begin{array}{c}0.000^{*} \\
(1.96)\end{array}$ & $\begin{array}{r}0.000 \\
(1.77)\end{array}$ & $\begin{array}{l}0.000 * \\
(1.83)\end{array}$ \\
\hline Organizational Size & -- & $\begin{array}{l}-0.007+ \\
(-1.74)\end{array}$ & $\begin{array}{l}-0.007+ \\
(-1.77)\end{array}$ & $\begin{array}{l}-0.007+ \\
(-1.80)\end{array}$ & $\begin{array}{l}-0.007+ \\
(-1.70)\end{array}$ & $\begin{array}{l}-0.007+ \\
(-1.67)\end{array}$ & $\begin{array}{l}-0.007+ \\
(-1.79)\end{array}$ & $\begin{array}{l}-0.006 \\
(-1.59)\end{array}$ \\
\hline Generalist Organization & -- & $\begin{array}{c}-0.300 \\
(-0.68)\end{array}$ & $\begin{array}{l}-0.211 \\
(-0.46)\end{array}$ & $\begin{array}{l}-0.226 \\
(-0.49)\end{array}$ & $\begin{array}{l}-0.237 \\
(-0.51)\end{array}$ & $\begin{array}{l}-0.169 \\
(-0.36)\end{array}$ & $\begin{array}{l}-0.159 \\
(-0.34)\end{array}$ & $\begin{array}{l}-0.121 \\
(-0.26)\end{array}$ \\
\hline Manhattan Based & $\begin{array}{c}0.93 * \\
(3.57)\end{array}$ & $\begin{array}{c}0.873^{*} \\
(-3.32)\end{array}$ & $\begin{array}{c}0.625^{*} \\
(2.21)\end{array}$ & $\begin{array}{l}0.609 * \\
(2.07)\end{array}$ & $\begin{array}{l}0.727 * * \\
(2.39)\end{array}$ & $\begin{array}{c}0.513 * \\
(1.71)\end{array}$ & $\begin{array}{l}0.613^{* *} \\
(2.06)\end{array}$ & $\begin{array}{c}0.620 * \\
(1.99)\end{array}$ \\
\hline Brooklyn/The Bronx Based & $\begin{array}{l}1.173 * \\
(3.48)\end{array}$ & $\begin{array}{l}1.100^{*} \\
(-3.24)\end{array}$ & $\begin{array}{l}1.066^{*} \\
(3.08)\end{array}$ & $\begin{array}{l}1.04 * * \\
(3.01)\end{array}$ & $\begin{array}{l}1.22 * * \\
(3.39)\end{array}$ & $\begin{array}{l}0.970 * * \\
(2.77)\end{array}$ & $\begin{array}{l}1.089 * * \\
(3.11)\end{array}$ & $\begin{array}{l}1.175^{* *} \\
(3.22)\end{array}$ \\
\hline Constant & $\begin{array}{c}-1.77 * \\
(-8.05)\end{array}$ & $\begin{array}{l}-1.44 * \\
(-5.15)\end{array}$ & $\begin{array}{l}-0.968 * \\
(-2.87)\end{array}$ & $\begin{array}{l}-0.994 * * \\
(-2.85)\end{array}$ & $\begin{array}{l}-0.385 \\
(-0.91)\end{array}$ & $\begin{array}{c}0.861 * \\
(-2.39)\end{array}$ & $\begin{array}{l}-0.645 \\
(-1.62)\end{array}$ & $\begin{array}{c}0.03 \\
(0.07)\end{array}$ \\
\hline Log Likelihood & -265.45 & -263.58 & -259.44 & -258.80 & -255.53 & -257.21 & -256.42 & -251.93 \\
\hline Degress of freedom & 2 & 4 & 6 & 8 & 9 & 9 & 10 & 12 \\
\hline Number of Cases & 484 & 484 & 479 & 479 & 479 & 479 & 479 & 479 \\
\hline
\end{tabular}


Figure 1: Cumulative Distribution of All Exchange Ties

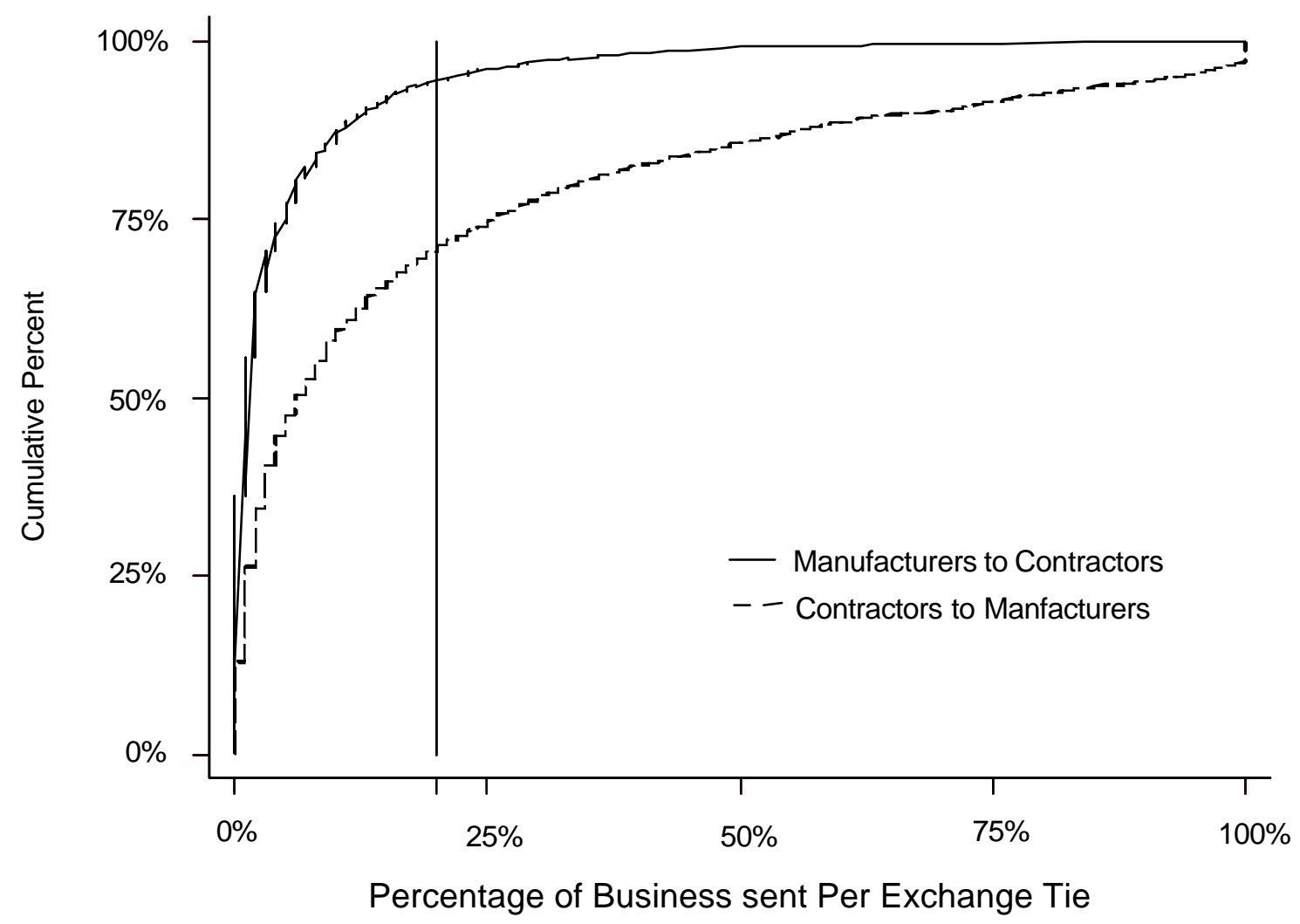


Figure 2: Cumulative Distribution of Principle Exchange Ties

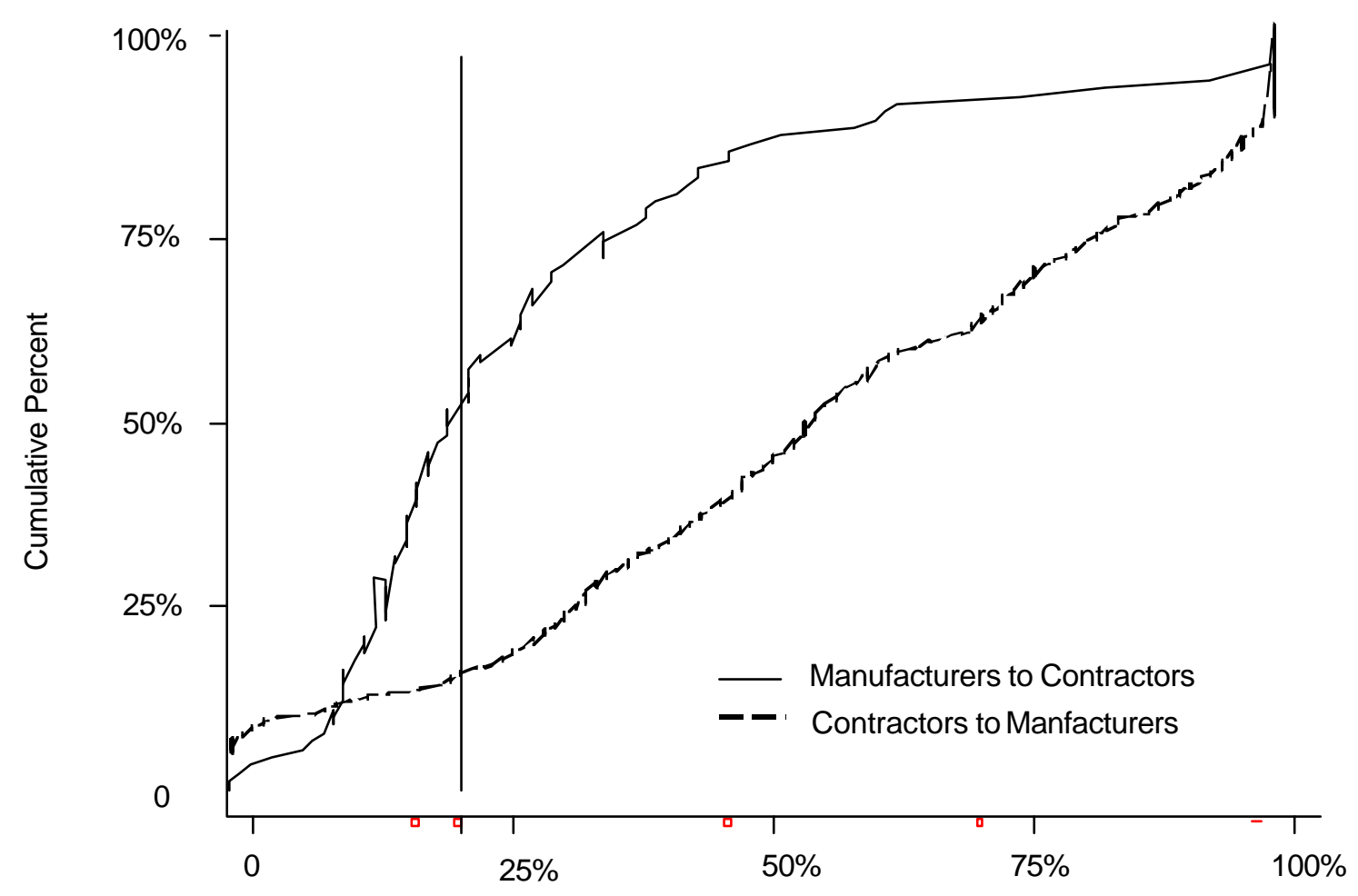

Percentage of Business sent Per Principle Exchange Tie 
Figure 3: Predicted Effect of 1st-Order Network Coupling on Failure

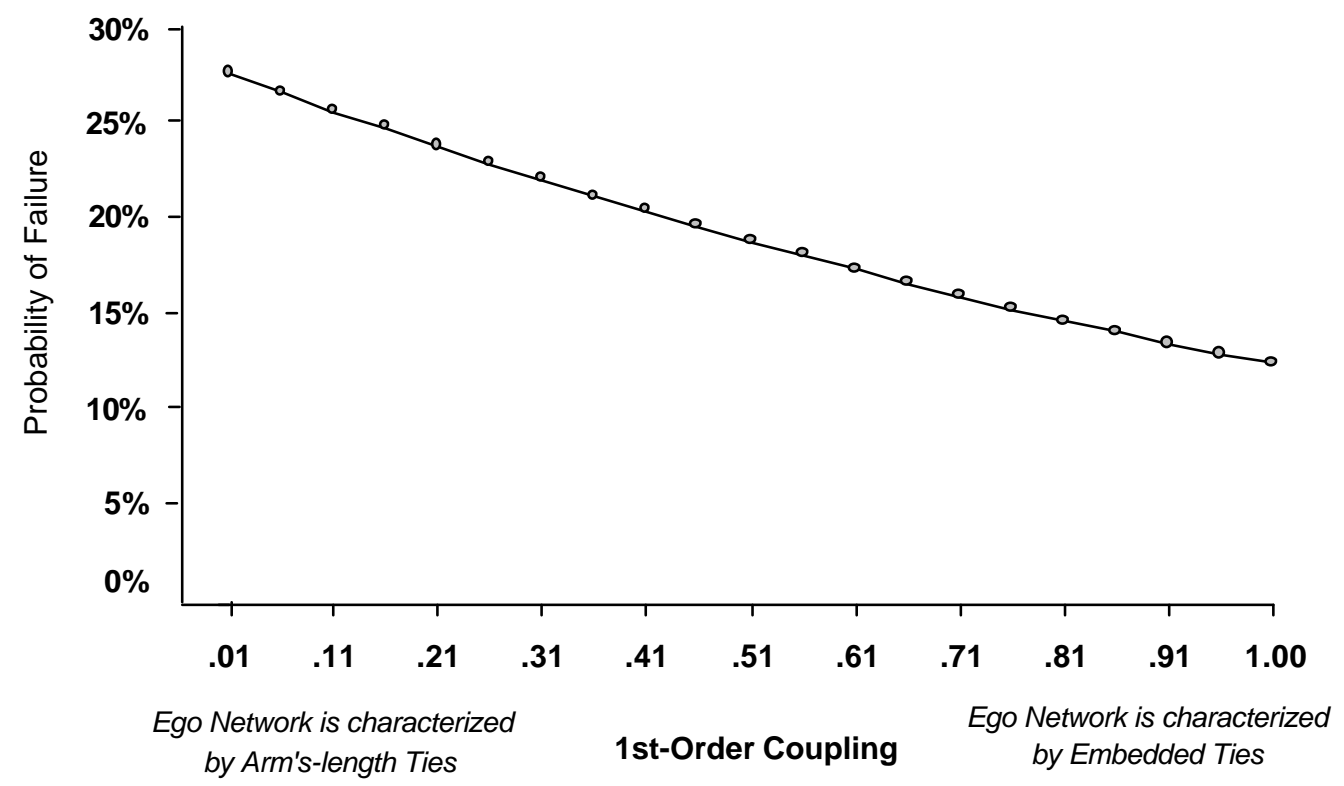


Figure 4:Predicted Effect of 2nd-Order Network Coupling on Failure

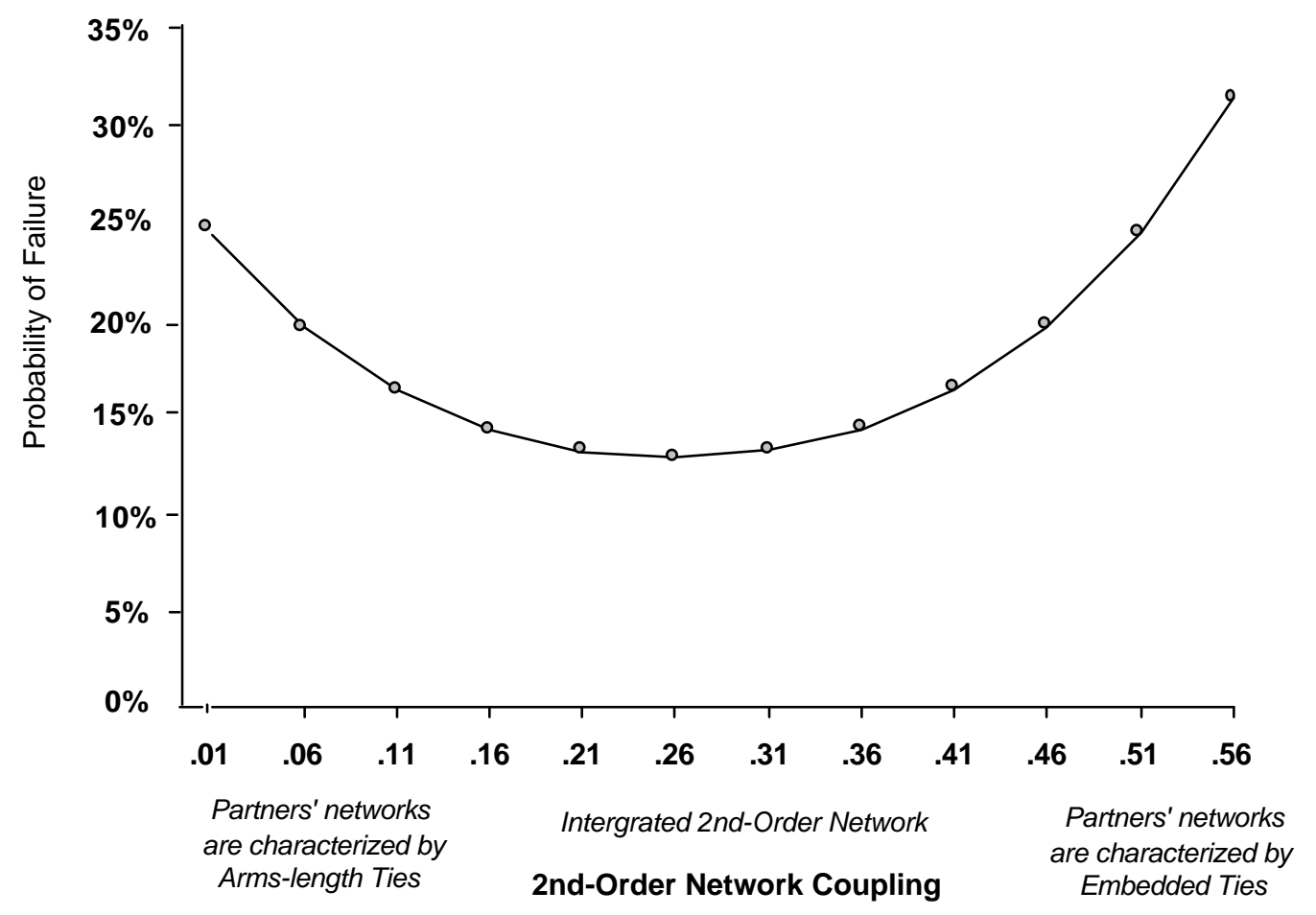


Figure 5: Predicted Effects of Embeddedness on Failure

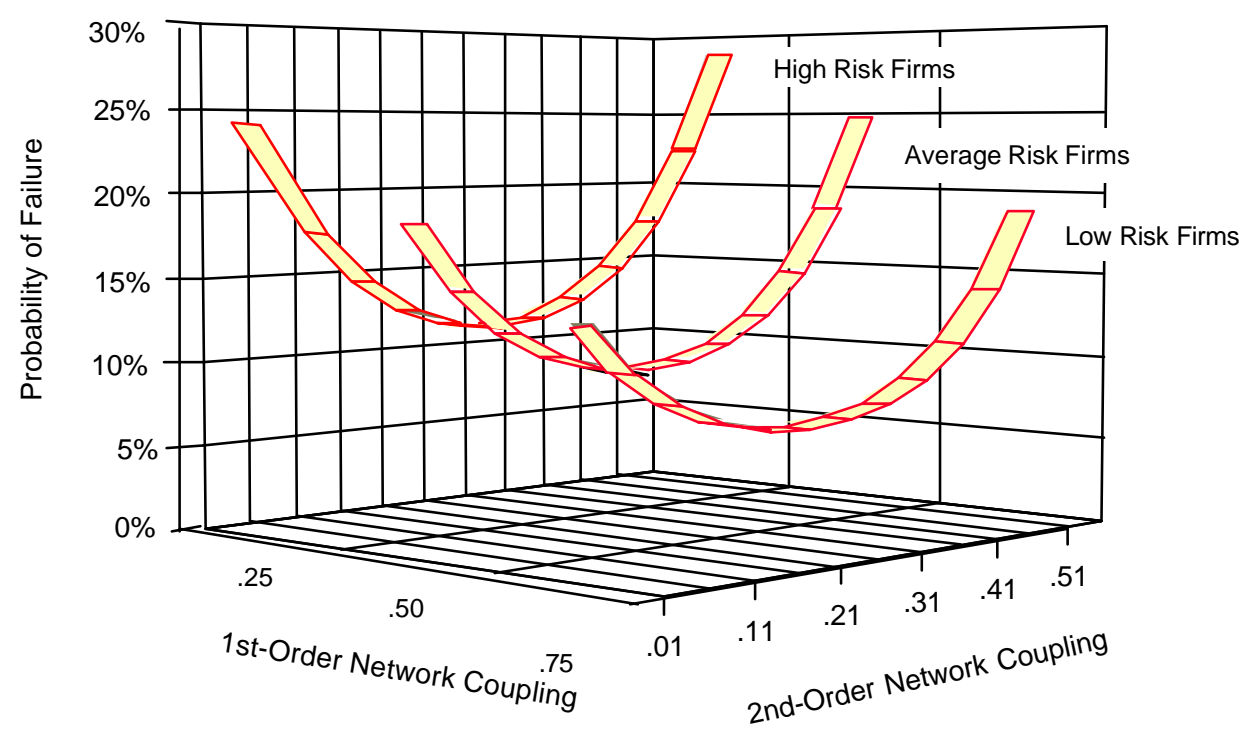

